\title{
On the Double-Rooted Trailing Edge Serration
}

\author{
P.C. Woodhead ${ }^{1}$, T.P. Chong ${ }^{2}$ and J.G. Wissink ${ }^{4}$ \\ Brunel University London, Uxbridge, UB8 $3 P H, U K$ \\ P.F. Joseph ${ }^{3}$ \\ University of Southampton, Southampton, SO17 1BJ, UK
}

\begin{abstract}
This paper investigates the next-generation serration technology for aerofoil trailing edge self-noise reduction. The core of the technique is to employ phase-cancellation between two sources that are physically displaced in a longitudinal direction. The mechanism is known as destructive interference when an $180^{\circ}$ out of phase occurs between the two sources. To the best knowledge of the authors, this is the first report on the use of double rooted serration to optimise trailing edge self-noise reduction. The study investigated four trailing edge configurations, Baseline (B), Single-Rooted Trailing Edge Serrations (SRooTES), DoubleRooted Trailing Edge Serration (DRooTES) and Slit trailing edges. At low-to-mid frequency range, the SRooTES demonstrates benefits at broadband noise reductions by the smallest serration wavelength $(\lambda)$ and largest serration amplitude (2h). However, no evidence of destructive interference exists between the root and the tip for the SRooTES. The next configuration of slit trailing edge successfully demonstrates the destructive interference mechanism between the root and tip, although constructive interference (when the phase angle reaches $2 \pi$ ) also occurs which accounts for the noise increase at higher frequency. Finally, the DRooTES has been proven to execute the destructive interference mechanism effectively between the double roots of the sawtooth. As a result, the DRooTES can achieve larger noise reduction than the SRooTES. Most importantly, the DRooTES allows one to fine-tune the frequency of interest for the self-noise reduction under a certain flow speed. However, it should be noted that the frequency-tuning for the DRooTES should take into account of other factors such as the pressure-driven secondary flow at the sawtooth side edges that will affect the celerity of the turbulent eddies in the boundary layer.
\end{abstract}

\section{Nomenclature}

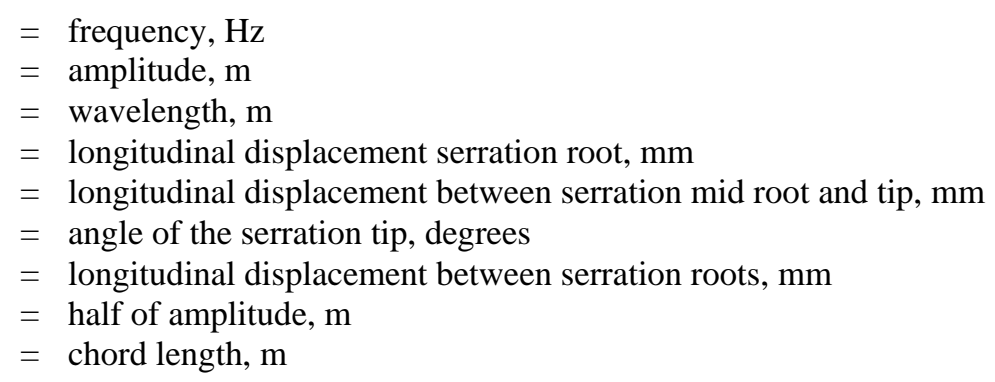

${ }^{1} \mathrm{PhD}$ Student, Department of Mechanical and Aerospace Engineering, philip.woodhead@brunel.ac.uk, non-AIAA Member (corresponding author).

${ }^{2}$ Senior Lecturer, Department of Mechanical and Aerospace Engineering, t.p.chong@ @brunel.ac.uk, AIAA Member.

${ }^{3}$ Professor, Institute of Sound and Vibration Research, pfj@ soton.ac.uk, AIAA Senior Member.

${ }^{4}$ Senior Lecturer, Department of Mechanical and Aerospace Engineering, jan.wissink@brunel.ac.uk, non-AIAA Member. 


$\begin{array}{ll}W & =\text { slit width at root, } \mathrm{mm} \\ a & =\text { slit width at tip, } \mathrm{mm} \\ \text { AoA, } \theta & =\text { Angle of Attack } \\ \Theta & =\text { Polar Angle, degrees } \\ \mathrm{U} & =\text { Freestream Velocity, } \mathrm{m} / \mathrm{s} \\ x & =\text { Position on aerofoil } \\ \mathrm{n} & =\text { convection velocity factor } \\ \mathrm{c} & =\text { pressure-driven vertical structure convection velocity difference } \\ \mathrm{PWL} & =\text { Sound Power Level, } \mathrm{dB} \\ \triangle \mathrm{PWL} & =\text { Difference in Sound Power Level, dB } \\ \text { OAPWL } & =\text { Overall Sound Power Level, } \mathrm{dB}\end{array}$

\section{Introduction}

T $\mathrm{T}$ is widely known that unwanted noise is essentially a form of pollution that affects health and wellbeing, especially

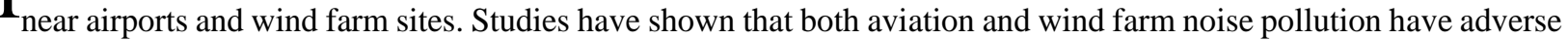
health effects resulting in annoyance, sleep disturbance and cognitive impairment $\mathrm{t}^{2-5}$. To protect the public, strict noise regulations have been implemented to both the aviation and wind energy sectors. The European Commission ${ }^{6}$ outlines aviation targets that in year 2050 aviation noise emission will be reduced by $65 \%$ compared to the level produced in 2000. However, civil aviation traffic is expected to expand worldwide between $4 \%$ and $5 \%$ annually with higher growth in the Middle East and Asia ${ }^{6}$. Similarly, Wind Europe ${ }^{7}$ issued a report in 2014 on the projected energy capacity scenarios in 2030, where their central scenario outlines that $320 \mathrm{GW}$ electricity will be generated by wind energy and that $78 \%$ of this would be produced by onshore wind farms.

The significant growth within the aviation industry and the onshore wind farms in the European Union (EU) member states would inevitably increase the aerodynamic noise pollution. The aircraft noise is mainly caused by the jet engine and high lift devices during takeoff and landing. However, development in technology of jet engines has seen a reduction in jet noise, but an increase in noise generated by the high bypass-ratio fan blades. The wind turbine mechanical noise is mainly caused by the moving parts inside the gearbox and generator ${ }^{8}$. However, the recent development of high precision gear tooth profile designs and acoustic insulation of casings has reduced the source of mechanical noise $\mathrm{e}^{9}$. In contrast, the aerodynamic noise generated from the wind turbine blade is more difficult to reduce. To protect local settlements, maximum noise levels are currently set at $35-45 \mathrm{~dB}(\mathrm{~A})$ at $350 \mathrm{~m}$ from the wind turbines ${ }^{10}$. As a result, wind turbine companies often reduce the rotation speed of their turbines at high wind speed scenario in order to curb the aerodynamic noise level not exceeding the prescribed limit. This practice essentially leads to a lower utilisation of the available wind energy source. Reduction of noise without reducing the rotor-speed would therefore make wind energy cheaper and, hence, a more attractive alternative for fossil energy. In quantitative term, a further $1 \mathrm{~dB}$ noise reduction than the current level can lead to significant increase in wind energy production. In other words, continue the research on wind turbine noise reduction is absolutely worthwhile and important for the promotion of clean energy.

Aerodynamic noise can emanate from the aerofoils' leading and trailing edges. The aerofoil noise is generated either at the leading edge of the blades, through interaction with the atmospheric turbulence, or at the trailing edges, where turbulence in the boundary layer develops on the blade's surface and scatters into sound ${ }^{11}$. For the trailing edge noise (also commonly referred to self-noise), it remains one of the most relevant noise sources related to the aviation and wind turbine industries. A comprehensive report on the physical aerofoil self-noise mechanisms can be found in Brooks et al. ${ }^{12}$.

The bio-inspired passive flow control device provides an attractive method of reducing aerodynamic noise at the leading and trailing edges. Leading edge serrations, also called undulations, tubercles, or protuberances, have seen significant benefits to the aerodynamic characteristics, at post-stall regime, and to acoustic characteristics. Hersh, Soderman and Hayden ${ }^{13}$, and Hersh and Hayden ${ }^{14}$ applied leading-edge serration to a two-blade rotor where they achieved tonal self-noise reduction between 4 and 6 dB. Hansen, Kelso and Doolan ${ }^{15}$ also observed significant tonal noise reduction with the addition of leading-edge serrations. Recently, a detailed study on the flow footprint on the aerofoil suction surface subjected to various types of serrated leading edges, and their effect on the far-field instability tonal noise radiation, has been reported by Chong et al. ${ }^{16}$. Leading edge serration is also found to be highly effective 
in suppressing another noise source, namely the turbulence-leading edge interaction noise. Clair et al. ${ }^{17}$ performed experimental and numerical works on a NACA 65-(12)10 aerofoil and found to achieve broadband noise reduction between 3 and $4 \mathrm{~dB}$. Narayanan et al. ${ }^{18}$ experimented on an aerofoil and flat plate where they observed reductions up to $7 \mathrm{~dB}$ for the aerofoil and $9 \mathrm{~dB}$ for the flat plate. Kim et al. ${ }^{19}$ performed a numerical study investigation the noise reduction mechanism through aerofoil interaction of turbulence mean flow. They found a decorrelation of surface pressure fluctuations on the serrated leading edge and the far-field spectra, which is not the case for the straight leading edge. In addition, the noise reduction at mid-to-high frequency range was the result of phase interference between the peak and mid-regions of the oblique edge of the serrated leading edge. Subsequently works by Chaitanya and Joseph ${ }^{1}$ explored an alternative profile of slits on the leading edge. They introduced a new control mechanism to produce compact source regions at either end of the slit, which reduces turbulence leading edge noise interaction through destructive interference. Essentially, inflow turbulence eddies of a representative integral scale reaches the slit opening will first scatter noise through the leading edge-turbulence interaction mechanism. The hydrodynamic disturbances will continue to propagate downstream. When reaching the slit root, another interaction noise scattering will happen. Because the same disturbances scatter twice at different spatial and temporal domains, the acoustic pressure waves can possibly cancel each other, which is the most effective when the phase angle between the two scattering is at $\pi$. Based on this concept, Chaitanya and Joseph ${ }^{1}$ achieved noise reductions of almost $18 \mathrm{~dB}$ at $40 \mathrm{~m} / \mathrm{s}$ for an optimised slit configuration in comparison to the conventional sawtooth leading edge profile of $7 \mathrm{~dB}$ of the same overall amplitude.

The sawtooth trailing edges, also known as serrations, were shown to be an effective passive flow control device to reduce turbulent boundary layer trailing edge noise. Studies have successfully demonstrated that sawtooth trailing edges can achieve noise reduction in wind tunnel experiments up to $8 \mathrm{~dB}^{20-23}$; whereas full-size wind turbine blades achieve reductions up to $3 \mathrm{~dB}^{11}$. A theoretical expression was developed by $\mathrm{Howe}^{24}$ to predict noise reduction by sawtooth trailing edge patterns. However, wind tunnel studies suggested that the predicted noise reduction was too optimistic. A theoretical model developed by Lyu et al..$^{25}$ provided a better noise prediction model, which was more comparable to the wind tunnel noise measurements. Gruber ${ }^{26}$ examined sawtooth trailing edges in a series of experiments where he investigated two common serration parameters: serration amplitude $(2 h)$ and serration wavelength $(\lambda)$. Furthermore, he demonstrated that sawtooth trailing edges achieved noise reductions up to $5 \mathrm{~dB}$ over a wide frequency range. He observed the following characteristics:

1. Self-noise reduction only happens when $\frac{h}{\delta}>0.25$ and $\frac{f \delta}{U}<1$, where $\delta$ is boundary layer thickness, $f$ is frequency $(\mathrm{Hz})$ and $U$ is freestream velocity. Enhancement in noise reduction occurred with larger serration amplitude and smaller serration wavelength.

2. At $\frac{h}{\delta}<0.25$, the serration amplitude became ineffective with the turbulent eddies passing over the serration surface.

3. Increase in high-frequency noise was suggested to be a result of the cross-flow between the serrations.

An experimental study by Chong and Vathylakis ${ }^{22}$ assessed turbulent flow over a flat plate with a serrated trailing edge. They found that variation in wall pressure power spectral density and in spanwise coherence played a minor role in the mechanisms that resulted in a reduction of self-noise radiation. Furthermore, they also observed the interaction between vortical structures and local turbulent boundary layers resulted in a redistribution of the momentum transport and turbulent shear stress near the oblique edges, as well as the tips of the serration. This affected the efficiency of the hydrodynamic pressure waves into trailing edge noise radiation. They also observed that interaction of hairpin vortices and the non-viscous, pressure driven oblique vortices led to significant levels of surface pressure fluctuations as well as the reduction in convection rates, to $43.8 \% \sim 57.9 \%$, of turbulence structures near the edges and tips of the serration. A subsequent study by Leon et al. ${ }^{21}$ investigated flow mechanisms using time-resolved stereoscopic Particle Imaginary Velocimetry (PIV). They observed significant changes to the flow as it passed over the serrations towards the serration edges. They proposed that the reduction of trailing edge noise was a result of reduction in shear stress and modification of the turbulence spectra as the flow passed over the serrations. Van der Velden et al. ${ }^{27}$ performed numerical works to link the relationship between the far-field and the flow-field on a NACA 0018 aerofoil with serrated trailing edges. They observed that the intensity of the surface pressure fluctuations varied within the streamwise direction and most of the low-frequency noise was generated at the roots of the serrations. Moreover, they suggested two statistical parameters, edge-oriented correlation length and convection velocity, that influence both the intensity of noise reduction and the frequency range of noise reduction, by generating destructive interference mechanisms between the pressure waves scattered along the slanted edge. 
To summarise the above short literature reviews, we identified three important characteristics pertaining to a serrated edge. First, noise reduction by a serrated trailing edge is partly related to destructive interference caused by a phase lag mechanism of turbulence noise scattering on the slanted/oblique edge. Second, the root of the serrated trailing edge is effective in turbulence noise radiation. Third, two noise sources that are displaced by $180^{\circ}$ phase angle in the longitudinal direction, such as the leading edge slit case, have been shown to be able to maximise the destructive interference for the aerodynamic noise reduction. The aim of this paper, therefore, is to create a second-order trailing edge serration root sources to produce the most optimised destructive interference mechanism for the trailing edge self-noise reduction. We call the new device: Double-Rooted Trailing Edge Serration (DRooTES), where for the first time, not only the level of trailing edge noise reduction can be improved, but also fine-tuning of the frequency of interest for the self-noise reduction becomes a possibility.

\section{Experimental Setup}

This section covers the experimental setup and the analysis techniques used to obtain the far-field noise measurements.

\section{A. Design of the NACA65-(12)10 aerofoil with add-on trailing edges}

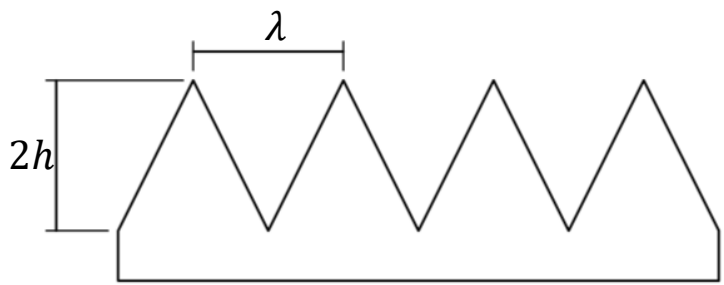

A) Single-Rooted-Serrations (SRooTES)

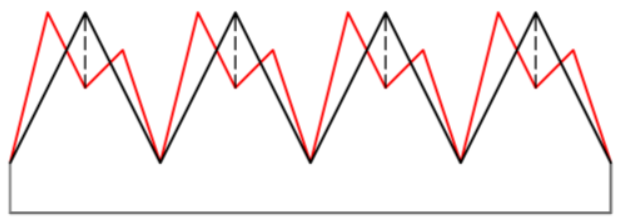

C) Comparison between the DRooTES and SRooTES

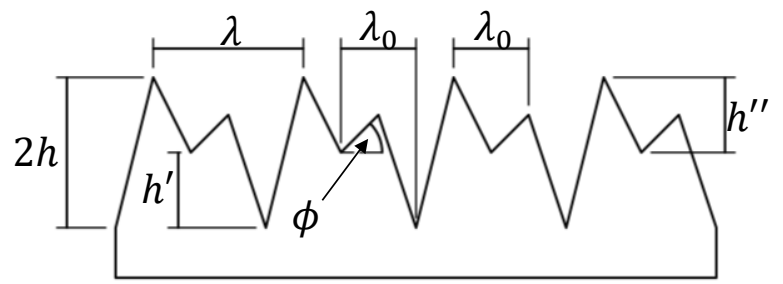

B) Double-Rooted-Serrations (DRooTES)

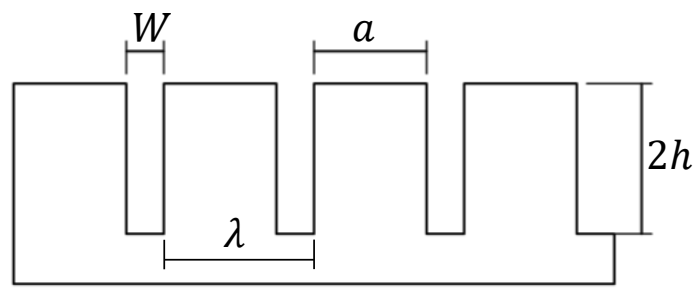

D) Slits

Figure 1: Geometric parameters of the SRooTES, DRooTES and Slit trailing edge add-on for the NACA65(12)10: amplitude $(2 h)$, wavelength $(\lambda)$, root-root longitudinal displacement of DRooTES $\left(h^{\prime}\right)$, root-tip longitudinal displacement of DRooTES $\left(h^{\prime \prime}\right)$, angle of the serration tip $(\phi)$, root-root lateral displacement of DRooTES $\left(\lambda_{0}\right)$, width of slit tip $(a)$ and width of slit root $(W)$.

A NACA65-(12)10 cambered aerofoil was used in previous studies by the Institute of Sound and Vibration Research (ISVR), University of Southampton ${ }^{26}$ and Brunel University London ${ }^{28,29}$. The NACA65-(12)10 aerofoil has a chord-length of $c_{0}=0.145 \mathrm{~m}$ to $c_{0}=0.170 \mathrm{~m}$ for serrated trailing edge cases, except for the Baseline (B), (unserrated) chord length of $c_{0}=0.1425 \mathrm{~m}$ to $c_{0}=0.155 \mathrm{~m}$, and a span-wise length of $0.45 \mathrm{~m}$. To ensure similar wetted surface areas, different chord lengths were used for the baseline and serrated cases. The chord-lengths of the unserrated trailing edge cases, B, were half of the chord lengths for the serrated trailing edges in Slits, Single-Rooted Serrations (SRooTES), and Double-Rooted Serrations (DRooTES). These acronyms are used throughout this study. Note that, basically, the SRooTES represents a simple sawtooth trailing edge. The aerofoil was constructed in two main parts: the main aerofoil body and the detachable flat plate trailing edge. The main aerofoil was manufactured from aluminium alloy with surface pressure taps across the upper and lower surfaces, and a $0.8 \mathrm{~mm}$ slot along the trailing edge. Detachable, flat plate of $0.8 \mathrm{~mm}$ thickness was laser cut to form various trailing edge shapes.

Figure 1 illustrates the geometric parameters of the trailing edge flat plate cases. These are defined as the serration amplitude $(2 h)$, serration wavelength $(\lambda)$, root-root longitudinal displacement $(h)$, root-tip longitudinal displacement 
$\left(h^{\prime \prime}\right)$, angle of the serration tip $(\phi)$ and lateral-displacement serration roots $\left(\lambda_{0}\right)$. Unless otherwise stated, the root-root longitudinal displacement $\left(h^{\prime}\right)$ and root-root lateral displacement $\left(\lambda_{0}\right)$ are half the amplitude $(2 h)$ and wavelength $(\lambda)$ respectively. The present study investigated four cases: B, SRooTES, DRooTES and Slit. The readers are advised to refer to Fig. 1 for the schematics illustrating these cases.

A $0.8 \mathrm{~mm}$ slot along the rear end of the main aerofoil body allows for insertion of $0.8 \mathrm{~mm}$ thickness flat plate trailing edges. The ranges of serration amplitude $(2 h)$ and wavelength $(\lambda)$ of the Slit, SRooTES and DRooTES were 5 $\mathrm{mm} \leq 2 h \leq 30 \mathrm{~mm}$ intervals of $5 \mathrm{~mm}$, and $3 \mathrm{~mm} \leq \lambda \leq 35 \mathrm{~mm}$ respectively. The root-root lateral displacement and angle of the serration tip of the DRooTES were $1.5 \mathrm{~mm} \leq \lambda_{0} \leq 4.5 \mathrm{~mm}$ interval of $1.5 \mathrm{~mm}$ and $0^{\circ} \leq \phi \leq 84.3^{\circ}$. The B trailing edge was half the amplitude of the serrated case, to ensure similar wetted surface area to both SRooTES and DRooTES. For the ease of comparison between SRooTES and DRooTES to the slit trailing edge the B trailing edge would also be assumed to be half the amplitude. A coarse sandpaper was applied to the upper and lower surfaces at $x / c_{0}=0.2, c_{0}=0.15 \mathrm{~m}$, to ensure the boundary layers were fully tripped to turbulent. The sandpaper strip had a width of $10 \mathrm{~mm}$ and a thickness of $0.95 \mathrm{~mm}$.

\section{Wind Tunnel Facilities and Instrumentation}

The wind tunnel facilities and instrumentation setup for the far-field noise measurement were performed in the aero-acoustics facility at Brunel University London, which consisted of an open jet wind tunnel within an anechoic chamber of $4 \mathrm{~m} \times 5 \mathrm{~m} \times 3.4 \mathrm{~m}$. The open jet nozzle dimension was $0.3 \mathrm{~m} \times 0.1 \mathrm{~m}$ (width $\mathrm{x}$ height). The aerofoil was attached to the side plates flush to the nozzle lips. The open jet wind tunnel had an operation capacity of up to $U=80$ $\mathrm{m} / \mathrm{s}$, with typical low turbulence flow between $0.1 \%$ and $0.2 \%{ }^{30}$. The background noise (without aerofoil, but with side plates) was largely contributed by the open jet noise, which was very low in comparison to the aerofoil self-noise level produced at the identical flow speed ${ }^{30}$. All far-field noise measurements were performed at the geometric angle of attack (AoA) $\theta=0^{\circ}$.

\section{B. Far-Field Array Noise Measurements}

The far-field array noise measurements were performed with eight G.R.A.S. half-inch condenser microphones (46AE) mounted at polar angles from $\Theta=50^{\circ}$ to $\Theta=120^{\circ}$ intervals of $\Theta=10^{\circ}$. The $\Theta=90^{\circ}$ microphone was positioned at the mid-span of the aerofoil and at $0.97 \mathrm{~m}$ above the trailing edge. Figure 2 illustration the experimental setup of the far-field array. A gain of $\pm 20 \mathrm{~dB}$ was applied to each microphone signal through the G.R.A.S. 12AX 4-Channel $\mathrm{CCP}$ amplifier. The data were acquired using a 16-bit analogue-digital card manufactured by National Instruments. The sampling frequency was $40 \mathrm{kHz}$ with a sampling time of 20 seconds. The data were windowed and the Power Spectral Density (PSD) of $1 \mathrm{~Hz}$ bandwidth was computed from a 1024 points FFT and a 50\% overlap time. The noise was calculated to obtain the Sound Power Level (PWL) assuming a spherical spreading of the sound waves from the trailing edge. Noise measurements were taken at various freestream velocities from $U=20 \mathrm{~m} / \mathrm{s}$ to $U=60 \mathrm{~m} / \mathrm{s}$, at $U$ $=10 \mathrm{~m} / \mathrm{s}$ intervals. 


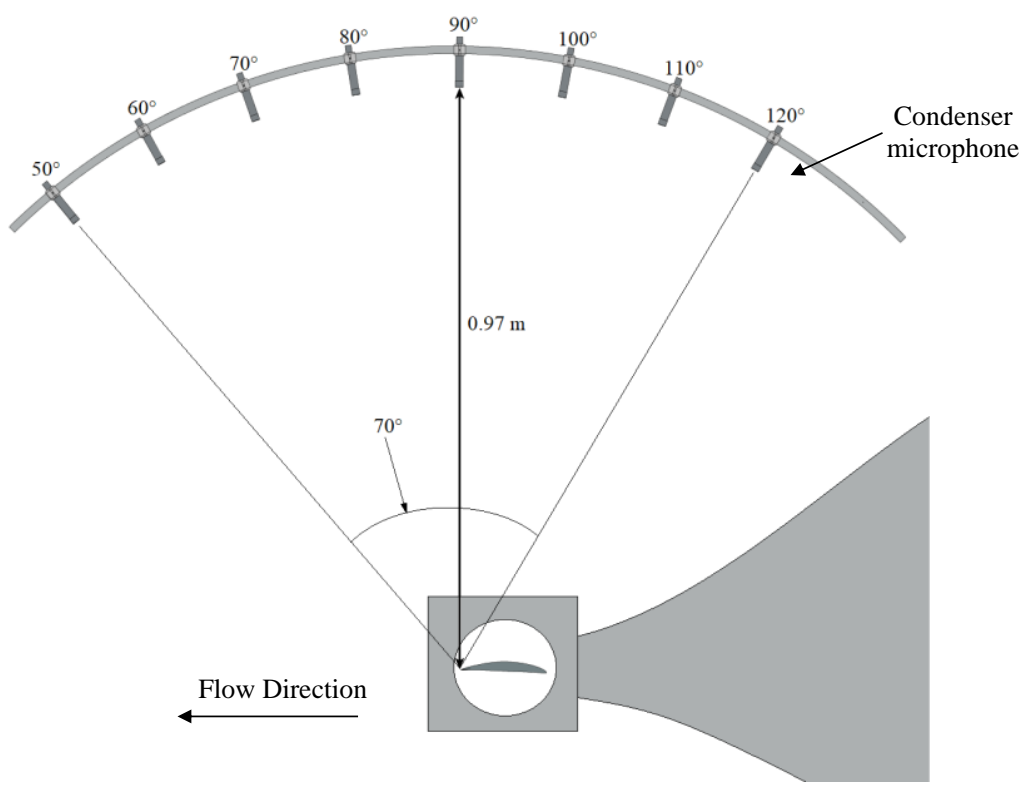

Figure 2: Schematic of the experimental setup of the far-field noise measurement where eight condenser microphones were positioned between $\Theta=50^{\circ}$ and $\Theta=120^{\circ}$ with intervals of $\Theta=10^{\circ}$ in an array positioned above the trailing edge of the aerofoil.

\section{Results and Discussion}

The results are presented in this section. The section covers the noise measurements obtained by the B, SRooTES DRooTES and Slit trailing edges at $U$ between 20 and $60 \mathrm{~m} / \mathrm{s}$, with an interval of $10 \mathrm{~m} / \mathrm{s}$, at $\theta=0^{\circ}$.

\section{SRooTES}

\section{A. Comparison of B, SRooTES and Background Noise Spectra}

Comparison of the Sound Power Level (PWL) between the background noise of the freestream jet flow, SRooTES and B trailing edges is shown in Figure 3. The background noise of the freestream jet flow was quieter than the quietest aerofoil self-noise generated by the SRooTES cases. A study by Vathylakis et al. ${ }^{30}$ performed background noise measurements within the same wind tunnel facilities and produced similar results. The SRooTES showed noise reduction up to $6 \mathrm{~dB}$ across the low-to-mid frequencies, $f=100 \mathrm{~Hz}$ to $f=2 \mathrm{kHz}$, in comparison to the B trailing edge. However, at the mid-to-high frequencies, $f>2 \mathrm{kHz}$, the SRooTES produced higher broadband noise levels than the B trailing edge. Studies by Gruber ${ }^{26}$ and Vathylakis et al. ${ }^{20}$ investigated flat-plate serrated trailing edges. They found comparable outcomes about the noise reduction at the low-to-mid frequencies, and noise increases at the mid-to-high frequencies. 

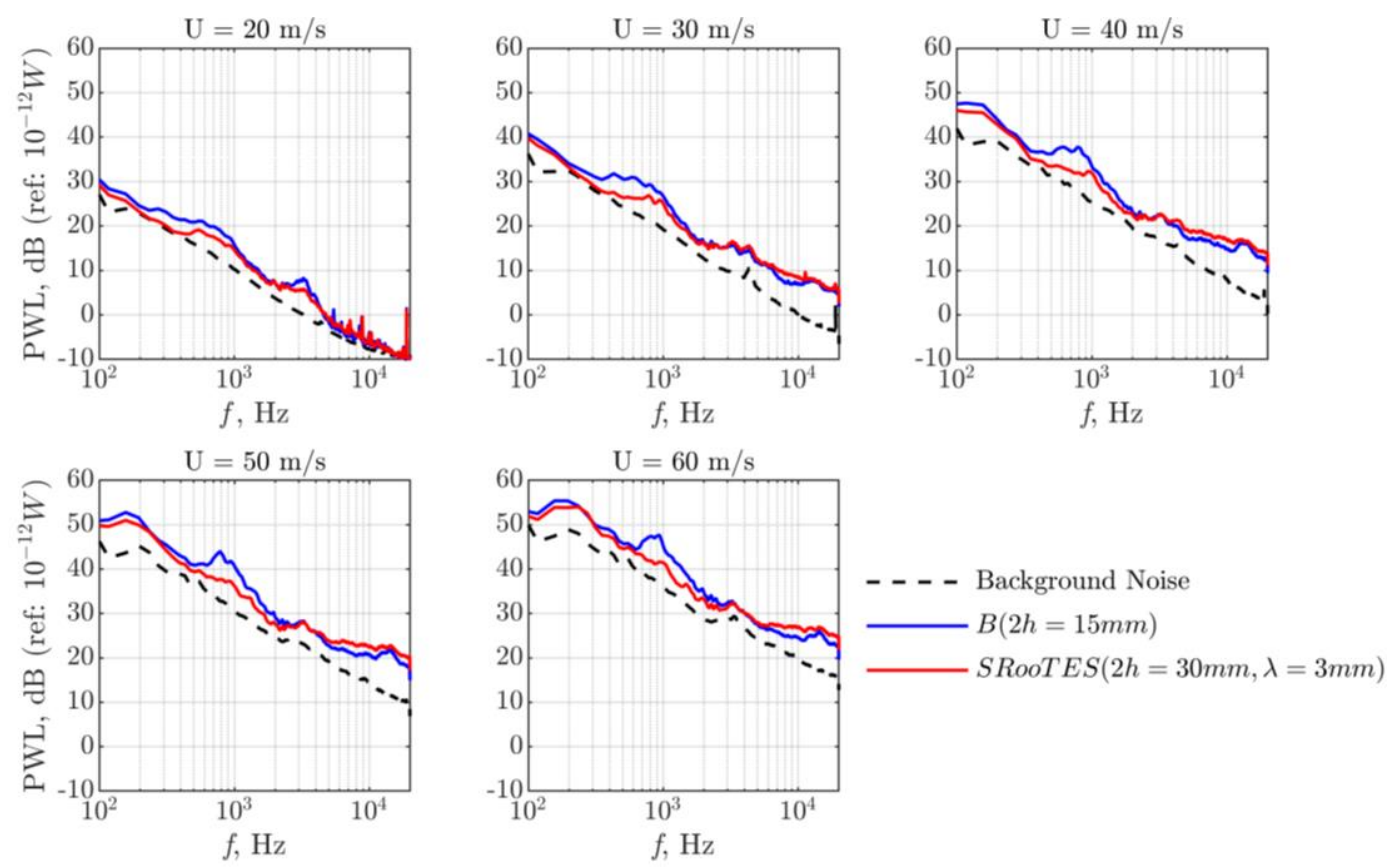

Figure 3: Comparison of the PWL, $\mathrm{dB}$ between SRooTES $(2 h=30 \mathrm{~mm}$ and $\lambda=3 \mathrm{~mm})$ and $\mathrm{B}$ trailing edge $(2 h=15 \mathrm{~mm})$ and background noise at various freestream velocities and $\theta=0^{\circ}$.

\section{B. Noise Comparison of Serration Amplitude (2h) of SRooTES}

Figure 4 shows the sensitivities of the broadband noise radiation for different amplitude, $2 h$, of the SRooTES. First, the result clearly demonstrates that the level of broadband noise reduction can be improved with an increase in serration amplitude, $2 h$. The largest amplitude, $2 h=30 \mathrm{~mm}$, was the most promising option for the SRooTES at lowto-mid frequencies, whereas $2 h=5 \mathrm{~mm}$ represented the worst option within the same frequency region. However, the SRooTES produced increase in broadband noise radiation at the high frequencies with increase in serration amplitude. Similar observations of high frequencies noise radiation by the serrations were confirmed by Gruber ${ }^{26}$, Leon et al. ${ }^{31}$, Vathylakis et al. ${ }^{20}$, Oerlemans et al. ${ }^{11}$ and Woodhead et al. ${ }^{29}$. Furthermore, Oerlemans et al. ${ }^{11}$ and Dassen et al. ${ }^{32}$ suggested that the increase in high frequency noise is a result of misalignment of the serrations to the freestream flow, which resulted in cross-flow between the serrations and led to an increase in high-frequency noise. SRooTES with $2 h$ $=30 \mathrm{~mm}$ produced the greatest noise increase in the high-frequency range, whereas the opposite is true for the smaller $2 h$ which produced the lowest noise increase amongst all the SRooTES. These observation in Figure 4 have been reported by Gruber ${ }^{26}$ and Vathylakis et al. ${ }^{20}$ whose aerofoil is the same one used in the current study. 

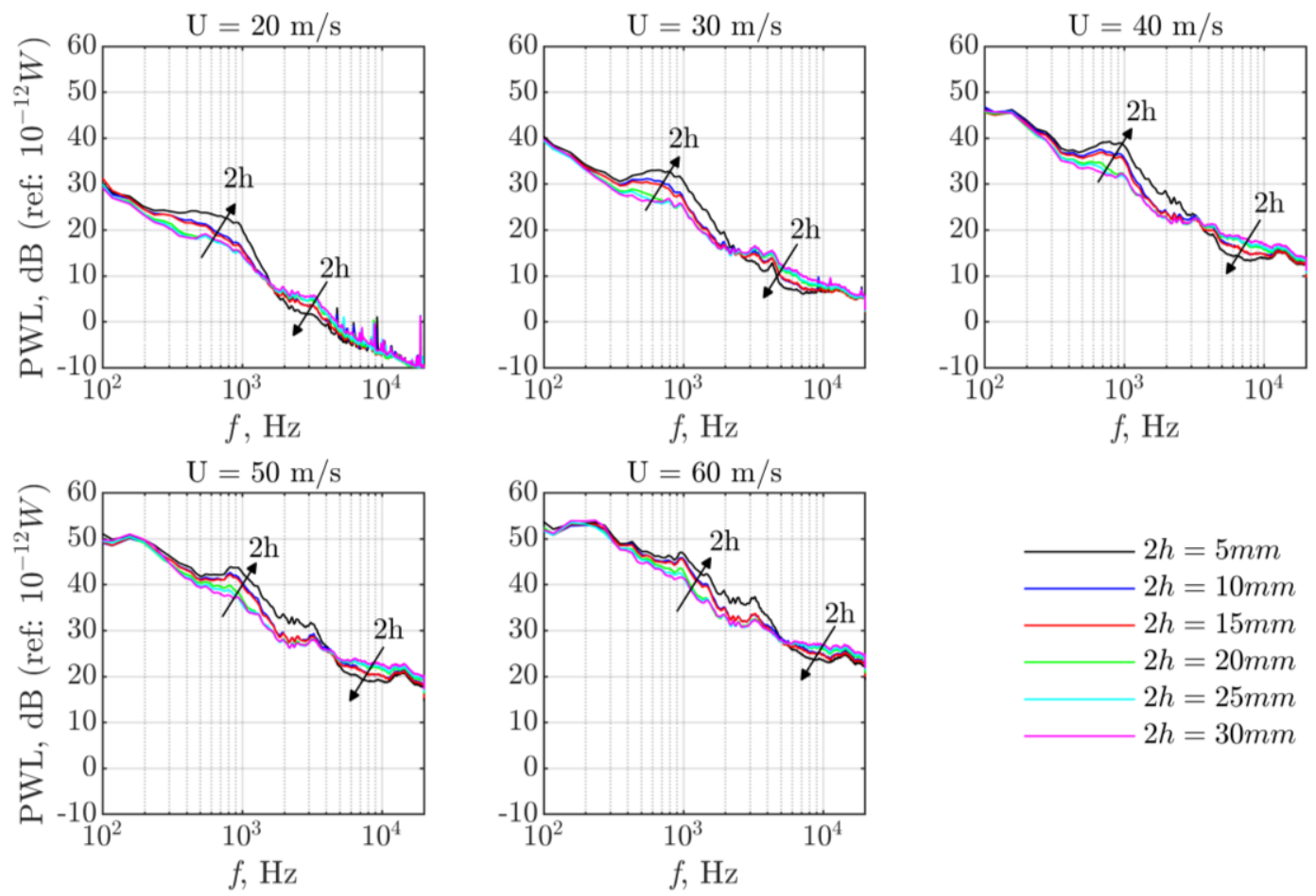

Figure 4: Comparison between the SRooTES (different $2 h$ ) trailing edges for PWL, dB, at $20 \mathrm{~m} / \mathrm{s} \leq U \leq 60$ $\mathrm{m} / \mathrm{s}$, and $\theta=0^{\circ}$.

\section{Noise Comparison of Serration Wavelength $(\lambda)$ of SRooTES}

Figure 5 presents the acoustic spectra for the SRooTES with different serration wavelength $\lambda$. The serration amplitude for them are kept the same at $2 h=30 \mathrm{~mm}$. $\triangle \mathrm{PWL}$ is defined as the difference in the sound power levels, as a function of frequency, between the B and SRooTES: $\triangle P W L(f)=P W L_{B}(f)-P W L_{S R o o t e s}(f)$. Note that a positive value of $\triangle \mathrm{PWL}$ represents noise reduction, and the opposite is true for a negative value. This definition also applies to the DRooTES and Slit cases, which will be discussed later. The results in Figure 5 follow largely the same trend as Gruber ${ }^{26}$. It is clearly shown that broadband noise reduction by SRooTES, achieved at $f<2.5 \mathrm{kHz}$, is more effective for a decreasing value of $\lambda$. For example, for the $\lambda=3 \mathrm{~mm}$, up to $5.5 \mathrm{~dB}$ reduction can be achieved. However, at high frequencies, $f>2.5 \mathrm{kHz}$, most of the SRooTES with small $\lambda$ are shown to produce noise level larger than the baseline case. In this context, a larger serration wavelength is desirable in order to avoid high frequency noise increase. In some cases, SRooTES with large $\lambda$ can actually harvest noise reduction up to $2 \mathrm{~dB}$ at high frequency. The different sensitivities of the noise radiation by SRooTES with respect to the $\lambda$ between low and high frequency means that there should be an intermediate configuration of SRooTES where $\triangle \mathrm{PWL}$ will remain positive throughout the frequency range. Indeed this is the case when $\lambda$ is around $15 \mathrm{~mm}$. 

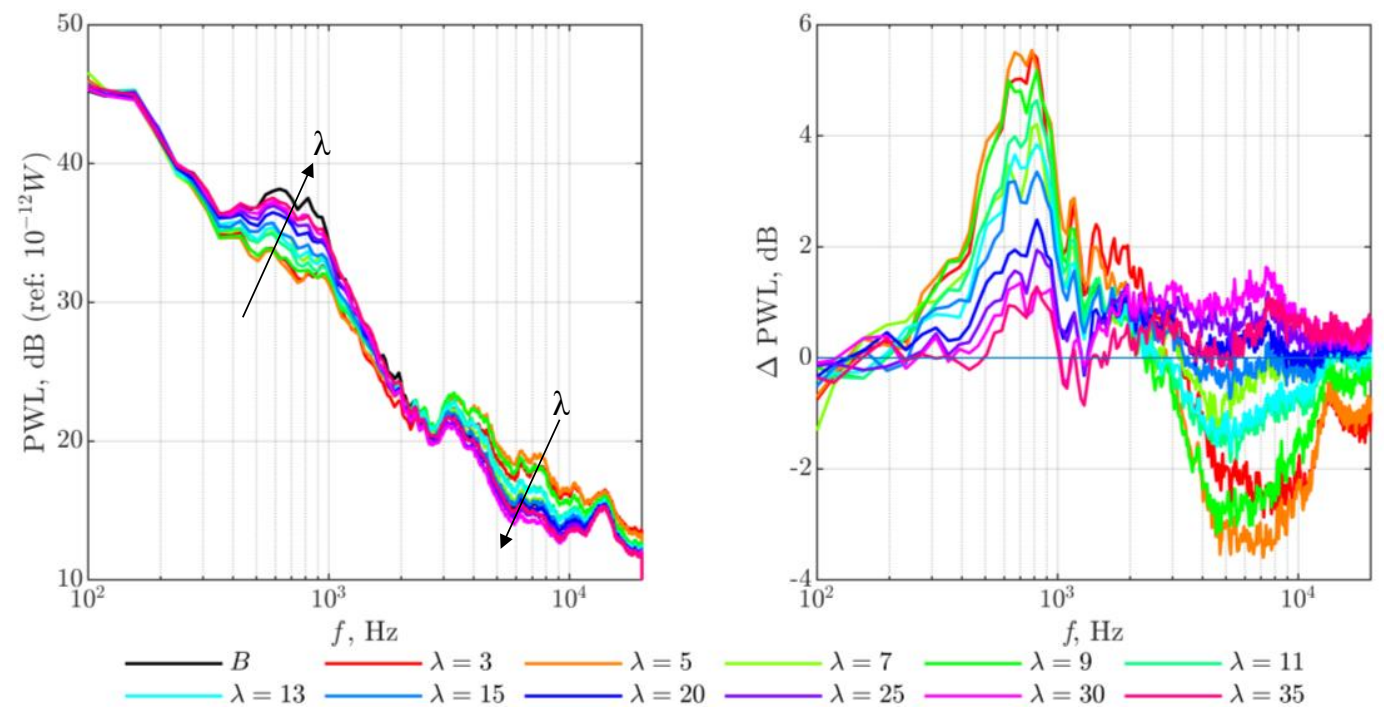

Figure 5: Comparison of SRooTES at different $\lambda$ with a constant $2 h=30 \mathrm{~mm}$ for: (a) PWL, $\mathrm{dB}$ and (b) $\triangle \mathrm{PWL}, \mathrm{dB} . \boldsymbol{U}=\mathbf{4 0} \mathrm{m} / \mathrm{s}$ and $\theta=0^{\circ}$.

\section{Non-Dimensional Frequency of SRooTES}

\section{i. Serration Amplitude}
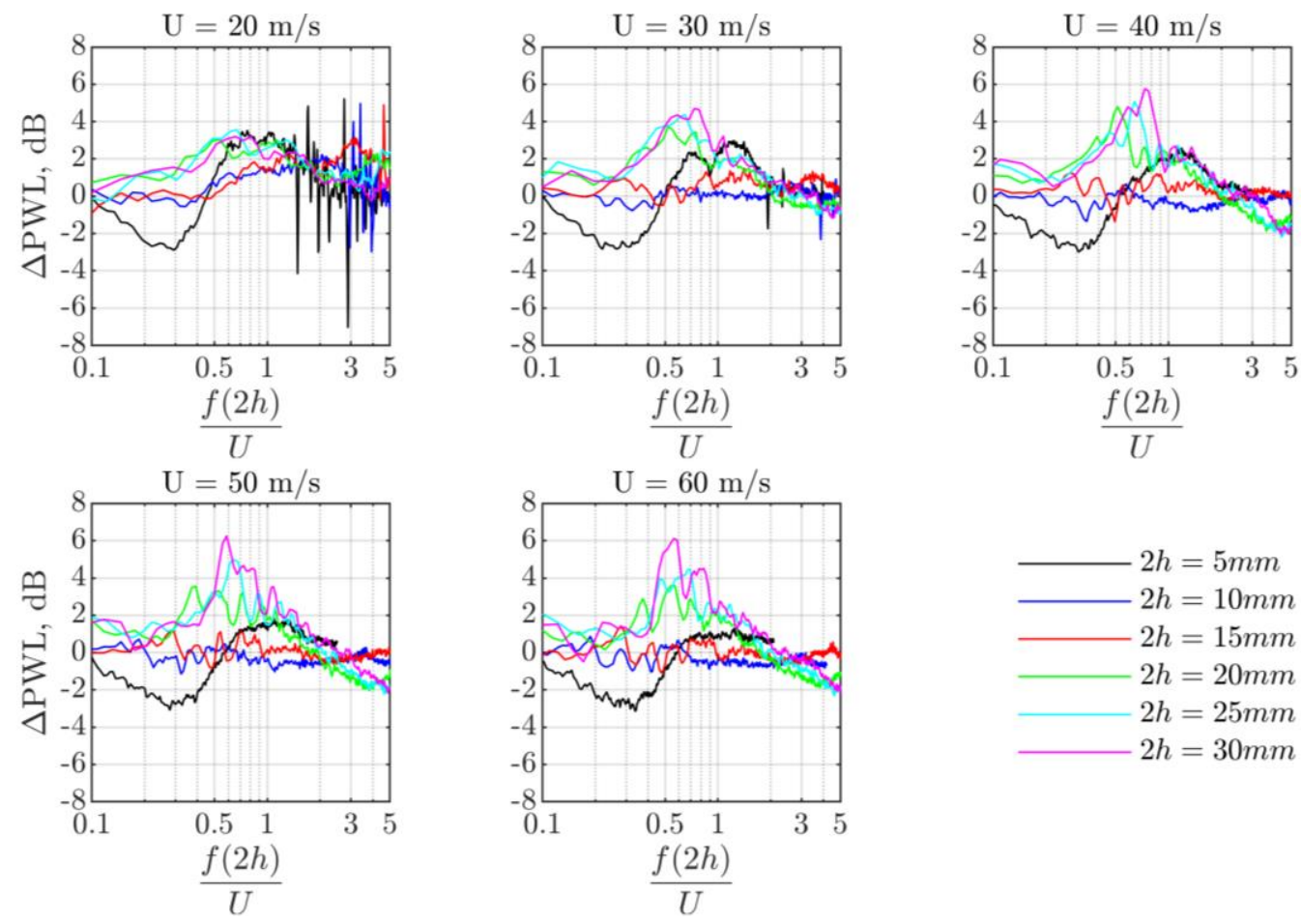

Figure 6: Non-Dimensional Frequency of the SRooTES at various $2 h . \lambda=3 \mathrm{~mm}, 20 \mathrm{~m} / \mathrm{s} \leq U \leq 60 \mathrm{~m} / \mathrm{s}$ and $\theta$ $=\mathbf{0}^{\circ}$. 
Figure 6 aims to determine whether by applying a non-dimensional frequency the broadband noise reduction of the SRooTES, at various serration amplitudes, can be generalised. The non-dimensional frequency, also known as the Strouhal number, is defined as:

$$
S t=\frac{f(2 h)}{u_{c}}, u_{c}=n U
$$

where $f$ is frequency, $2 h$ is the longitudinal displacement between the root and tip, $U$ is the freestream velocity, $u_{c}$ is the convection velocity of the turbulent eddies, and $n$ is the convection velocity factor. A study by Sagrado ${ }^{33}$ stated $^{2}$ that the convection factors at the trailing edges of the aerofoil are between $n=0.5$ and 0.8 . In the current study, the factor of $n=0.8$ is adopted. In theory, a perfect destructive interference is underpinned by the situation when the acoustic radiations are at $180^{\circ}$ out of phase between the two sources, resulting in cancellation of the acoustic radiation. This also means that the Strouhal number St should be equal to 0.5. However, the results in Figure 6 clearly demonstrated no relationship between the phase cancellation (or destructive interference) between the tip and root, and noise reduction achieved by the SRooTES. This was demonstrated by the discrepancy of various peak $\Delta \mathrm{PWL}$ scattering over a large range of non-dimensional frequency, between $S t=0.6$ and 1 , across the different $2 h$. Furthermore, at $U=20 \mathrm{~m} / \mathrm{s}$ the SRooTES showed no distinctive maximum noise reduction peaks. Figure 7 shows contour map of $\triangle \mathrm{PWL}$ against $f$ and $2 h$ achieved by the SRooTES at various $U$. The results in Figure 7 clearly demonstrate that noise reduction achieved by SRooTES cannot be characterised by the non-dimensional frequencies, shown by black line representing $S t=0.5$. Also, note that the majority of the SRooTES broadband noise reduction was achieved at $2 h \geq 20 \mathrm{~mm}$.

Therefore, noise reduction mechanism depicted in Figure 8 is not true for the SRooTES. In other words, the sawtooth tip is unlikely a noise source.
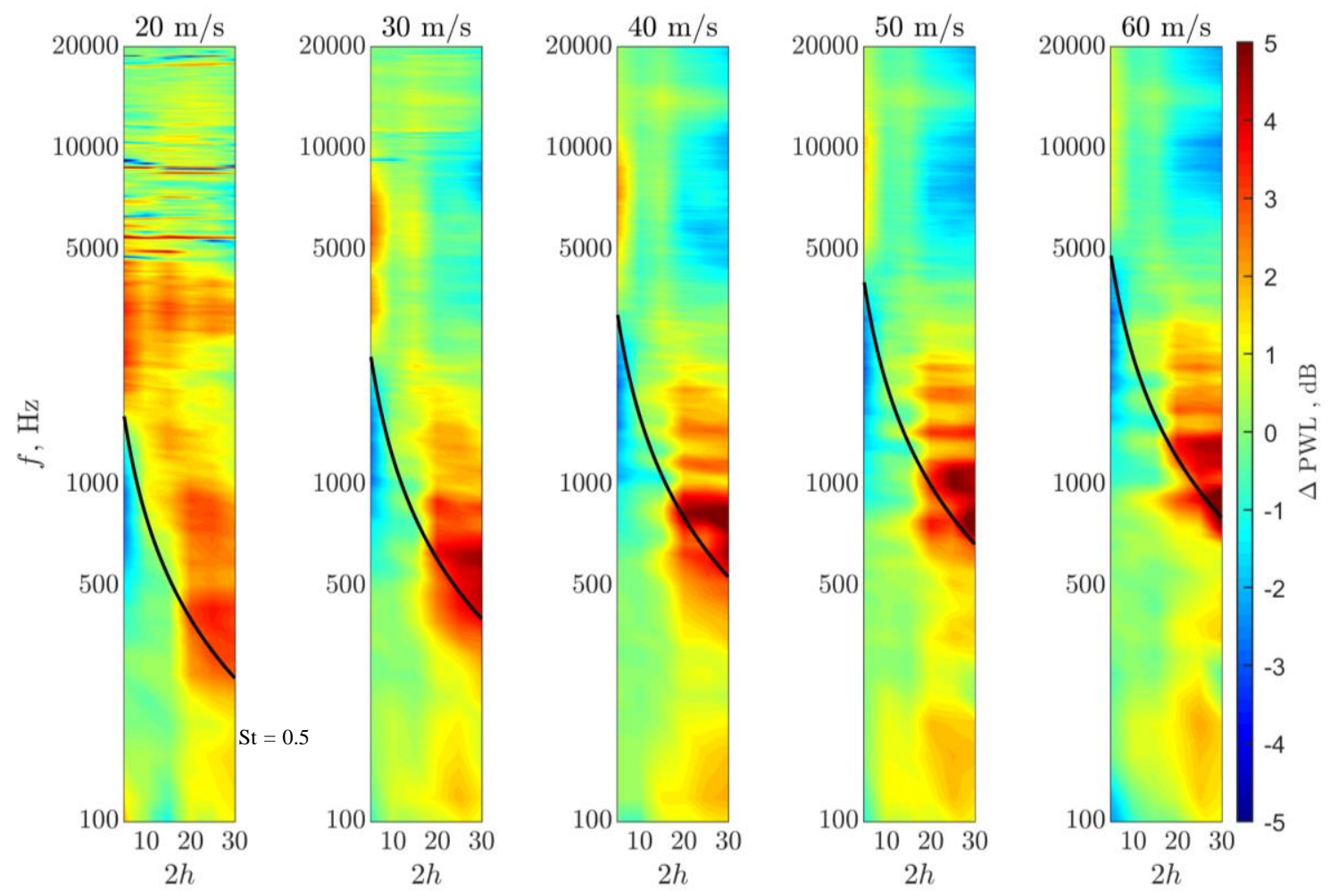

Figure 7: $\triangle \mathrm{PWL}$ contour maps of the frequency, $\mathrm{Hz}$, to $2 h$ for the SRooTES at different $U$ and $\theta=0^{\circ}$. 


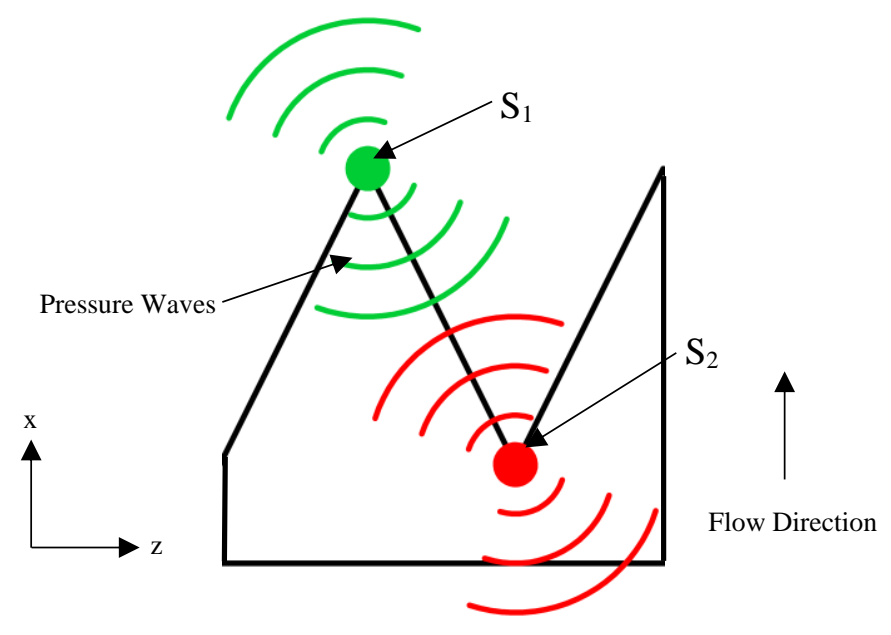

Figure 8: An initial hypothesis of destructive interference caused by two sources $\left(S_{1} \& S_{2}\right)$ for the SRooTES.

\section{Slit}

\section{A. Comparison of the Noise Measurements of the Slit Amplitude}

The next investigation is to examine the broadband noise radiation by the slit and B trailing edges at various $2 h$. It should be noted that, to maintain the same algorithm as the SRooTES and DRooTES, $\Delta$ PWL calculated for each slit trailing edge of a particular $2 h$ is also measured against a baseline with half-length $(h)$. The obvious uncertainty for this definition, albeit of minor nature, is that the wetted area might not be completely compatible to each other due to the variable widths of the slit investigated in this study.

Figure 9 shows that slit trailing edge is the most effective in producing further noise reduction at low-to-mid frequency range, up to $7 \mathrm{~dB}$. However, the slit trailing edge can also result in a significant degradation at high frequency where in most cases they result in significant broadband noise increase, up to $5 \mathrm{~dB}$, in comparison to the $\mathrm{B}$ trailing edge. In addition, distinctive peaks of noise reduction $\triangle \mathrm{PWL}$ are found to occur at different frequencies. The level of the maximum noise reduction $\triangle \mathrm{PWL}$ achieved by individual slit trailing edges appears not following a particular trend of slit amplitude $2 h$ across the $U$. 


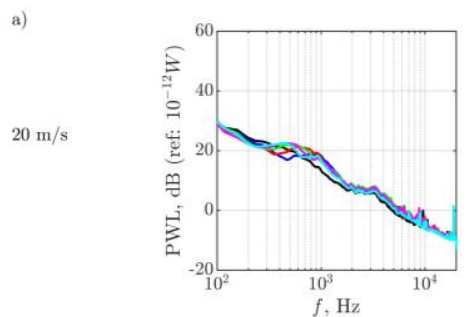

c)

$30 \mathrm{~m} / \mathrm{s}$

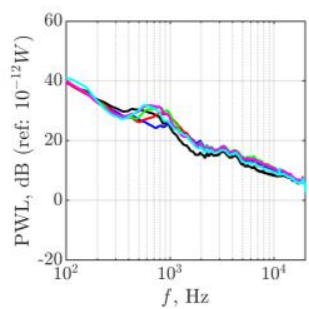

e)

$40 \mathrm{~m} / \mathrm{s}$

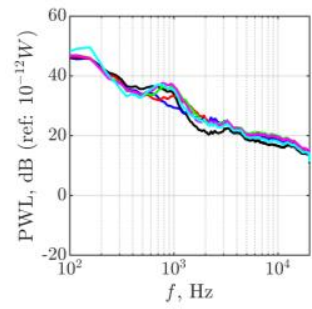

g)

$50 \mathrm{~m} / \mathrm{s}$

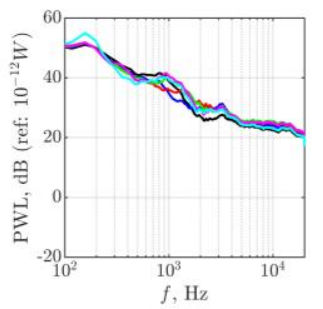

i)

$60 \mathrm{~m} / \mathrm{s}$

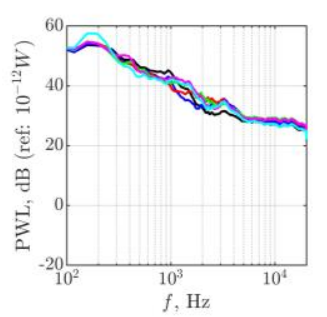

b)

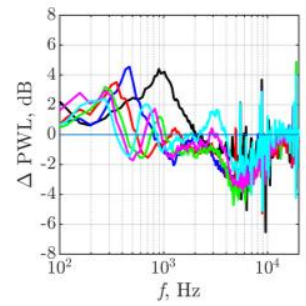

d)

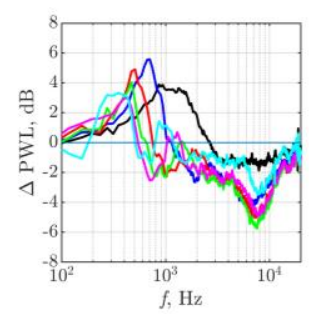

f)

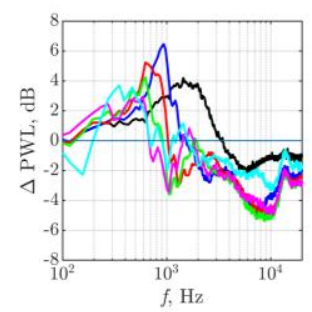

h)

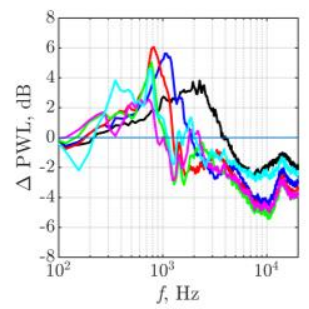

j)

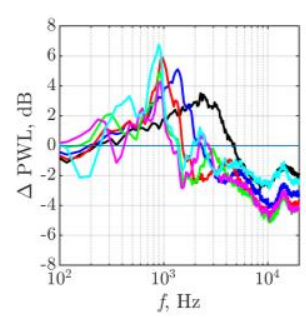

Figure 9: Comparison between the B and Slit (different $2 h$ ) trailing edges for: (a), (c), (e), (g), (i) PWL, dB and (b), (d), (f), (h), (j) $\triangle \mathrm{PWL}, \mathrm{dB}$ and at $\theta=0^{\circ}$.

\section{A. Comparison of the Noise Results at Different Wavelength $(\lambda)$, and Constant Width of Slit Root $(W)$}

Figure 10 presents a comparison of the sensitivity of broadband noise radiation at various $\lambda$ of the slit trailing edges, where the slit width $W$ was kept constant at $0.3 \mathrm{~mm}$. The results clearly showed that $\lambda$ plays a significant role in the noise characteristics of the slit trailing edge. Amongst all the slit trailing edges, the best performer is always the smallest $\lambda$ with noise reduction up to $6 \mathrm{~dB}$ at high $U$. When $\lambda$ increases, the level of noise reduction becomes less prominent. The results suggest that the noise scattering efficiency by the turbulent eddies at the edge will not be affected considerably under a single slit with a small $W / \Lambda$, ratio between the slit width and spanwise integral length scale of the turbulent eddies. However, if the spanwise spacing between the slits (i.e. $\lambda$ ) is small enough to fit multiple 
slits within a spanwise integral length scale of turbulent eddies, a much improved noise reduction performance can be achieved.

On the other hand, at high-frequency range the opposite trend can be observed. The slit trailing edge with the smallest $\lambda=3 \mathrm{~mm}$ produced the largest noise increase of $6.5 \mathrm{~dB}$. This might be because a small $\lambda$ will contain more slits, which in turn facilitate a greater level of cross-flow causing high frequency noise increase. As expected, the $\Delta \mathrm{PWL}$ performance recovers slowly, albeit non-linearly, as $\lambda$ increases. In particular, $\lambda=15 \mathrm{~mm}$ produces the least noise increase at the high frequency.

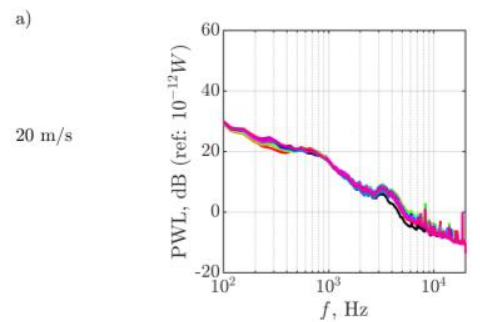

c)

$30 \mathrm{~m} / \mathrm{s}$

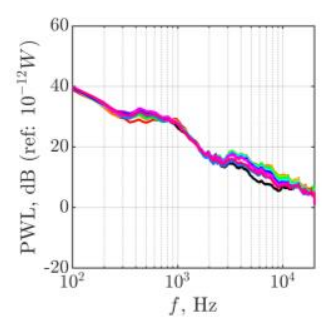

e)

$40 \mathrm{~m} / \mathrm{s}$

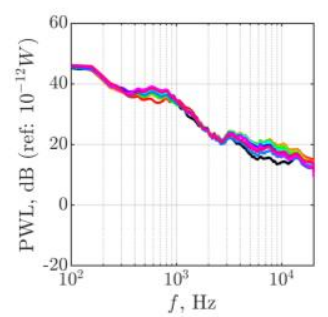

g)

$50 \mathrm{~m} / \mathrm{s}$

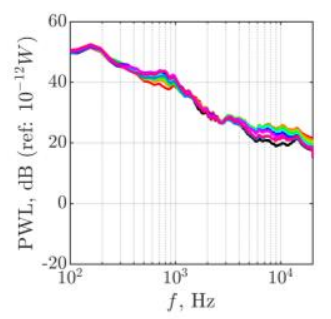

i)

i)

$60 \mathrm{~m} / \mathrm{s}$

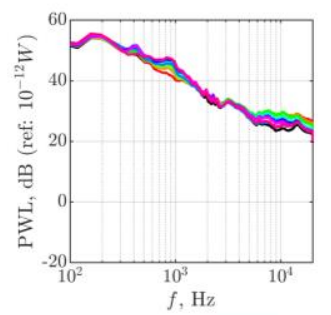

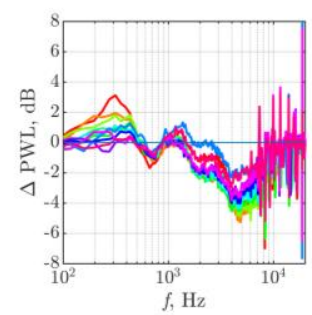

d)

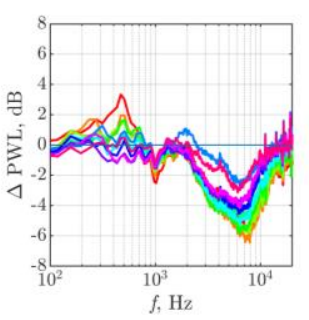

f)

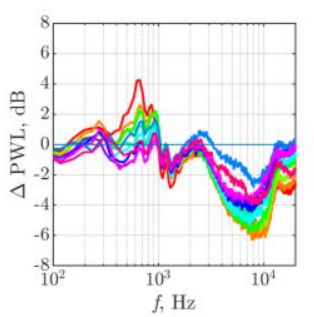

h)

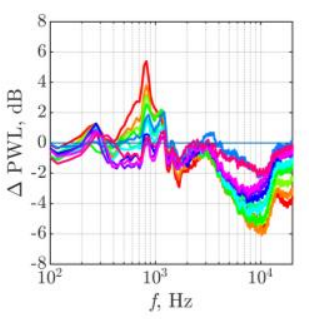

j)

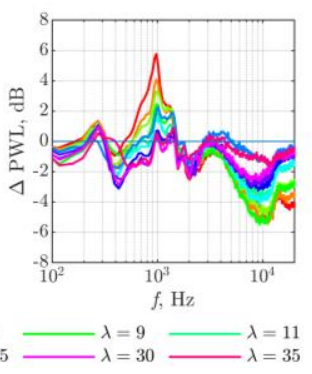

Figure 10: Comparison between the $B$ and Slit (different $\lambda$, same $W$ ) trailing edges for: (a), (c), (e), (g), (i) PWL, dB and (b), (d), (f), (h), (j) $\triangle \mathrm{PWL}, \mathrm{dB}$ and at $\theta=0^{\circ}$. 


\section{B. Comparison of the Noise Results at Different Width of Slit $\operatorname{Root}(W)$, and a Constant Wavelength $(\lambda)$}

Figure 11 presents a comparison of the broadband noise radiation for slit trailing edge at different aspect ratio of $W / \lambda$, where $\lambda$ was kept constant at $3 \mathrm{~mm}$. The results clearly demonstrate that as $W$ increases, significant degradation of the noise performance occurs at low-to-mid frequencies across all $U$. When $W$ increases, the slit geometry will become more compatible and eventually exceed the spanwise integral length scale of the turbulent eddies. In this case, the slit at the root region will slowly revert to a straight trailing edge noise mechanism, and in turn reduce the noise reduction capability.

Amongst all the cases, the best performer is $W / \lambda=0.15$ with reduction up to $6 \mathrm{~dB}$, whereas the worst performer is with the largest $W / \lambda=0.5$. At mid-to-high frequencies, $600 \mathrm{~Hz}<f<20 \mathrm{kHz}$, it can be observed that the largest $W / \lambda$ $(=0.5)$ is the only configuration that does not result in noise increase. It can even achieve a slight broadband noise reduction up to $4 \mathrm{~dB}$ at low $U$. All the smaller $W / \lambda$ configurations, on the other hand, only produce noise increase. The smaller the $W / \lambda$, the larger noise increase it happens. Based on the results presented thus far, the following statements can be summarised:

1) Small $W / \lambda$ configuration is desirable for broadband noise reduction at low-to-mid frequency. This is to avoid the slit width becoming too compatible with the spanwise integral length scale of the turbulent eddies.

2) Large $W / \lambda$ configuration is desirable to avoid noise increase at high frequency. This is to reduce the tendency of cross-flow across the slit and minimise the flow leakage. 
a)

$20 \mathrm{~m} / \mathrm{s}$

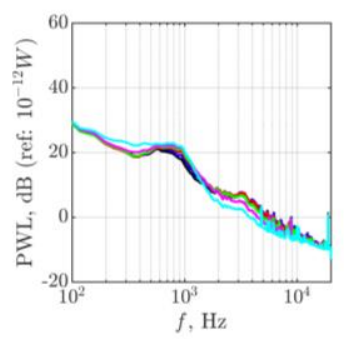

$30 \mathrm{~m} / \mathrm{s}$

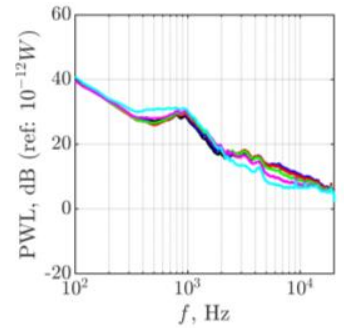

e)

$40 \mathrm{~m} / \mathrm{s}$

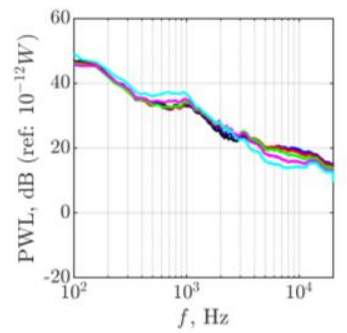

g)

$50 \mathrm{~m} / \mathrm{s}$

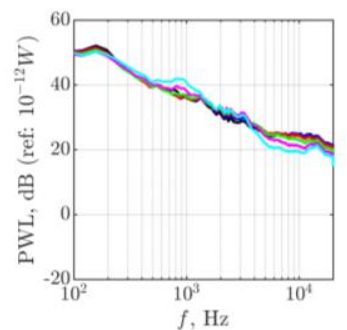

$60 \mathrm{~m} / \mathrm{s}$

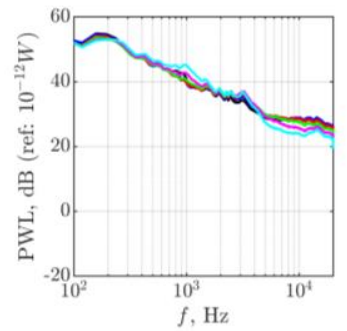

b)

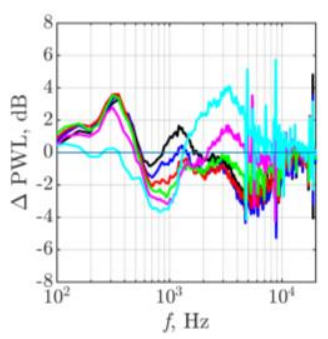

d)

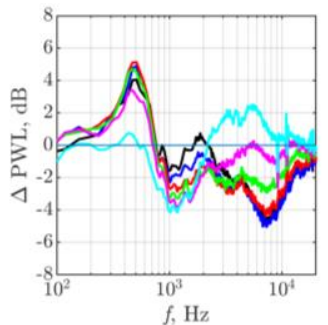

f)

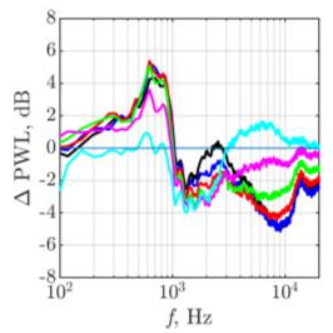

h)

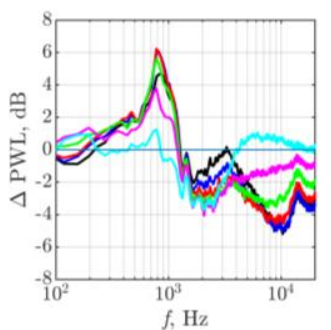

j)

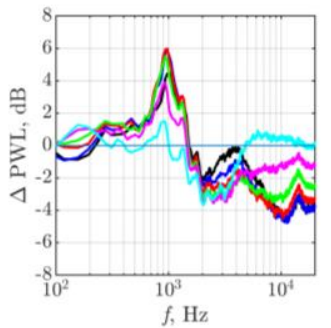

$W / \lambda=0.05$

$W / \lambda=0.15$

$-W / \lambda=0.2$

$W / \lambda=0.3 \longrightarrow W / \lambda=0.5$

Figure 11: Comparison between the $B$ and Slit (different $W / \lambda$, but with the same $\lambda$ ) trailing edges for: a), (c), (e), (g), (i) PWL, dB and (b), (d), (f), (h), (j) $\Delta \mathrm{PWL}, \mathrm{dB}, 2 h=15 \mathrm{~mm}, \lambda=3 \mathrm{~mm}$ and at $\theta=0^{\circ}$. 


\section{Non-Dimensional Frequency of Slit Trailing Edges}
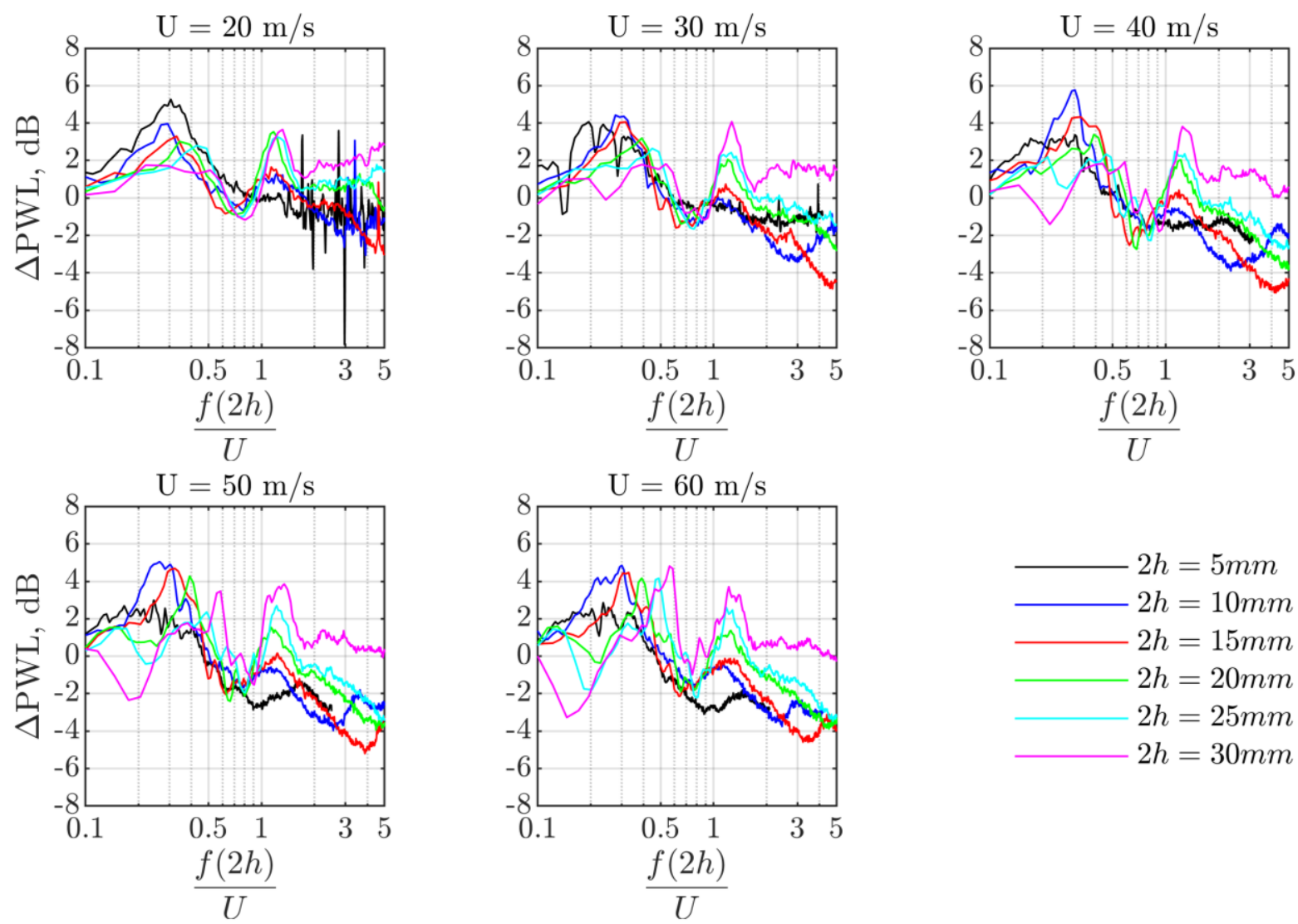

Figure 12: Non-Dimensional Frequency at various slit amplitudes $2 h, \lambda=3 \mathrm{~mm}, U=20 \mathrm{~m} / \mathrm{s}$ to $U=60 \mathrm{~m} / \mathrm{s}$ and $\theta=0^{\circ}$.

The slit trailing edges have so far proven to be advantageous at reducing broadband noise at low-to-mid frequencies. As shown in Figure 12, attempt to non-dimensionalise the frequency in the same manner as the SRooTES results in the peak $\Delta \mathrm{PWL}$ taking place at around the Strouhal number $S t=0.3$ for different slit amplitudes (except for the $U=60 \mathrm{~m} / \mathrm{s}$, where a slight fluctuation of Strouhal number is evident). This suggests that destructive interference mechanism might be responsible for the noise reduction despite the deviation of the theoretical Strouhal number $S t=$ 0.5 pertaining to the $180^{\circ}$ out of phase cancellation between the two sources (root and tip). Three potentially factors that affect the non-dimensional frequency are:

1) Turbulent eddies scatter into pressure waves in close proximity to the roots, not exactly at the root, which can affect the "true" longitudinal displacement between roots and tips of the slit.

2) Variation of the convection velocity factor ranges between 0.4 and 0.75 .

3) Additional factor affecting the convection speed of the turbulent eddies due to the presence of secondary flows (e.g. the cross-flow within the slit).

Figure 12 clearly demonstrates that all the peak $\triangle \mathrm{PWL}$ pertaining to the slit configurations is followed by a significant dip of $\triangle \mathrm{PWL}$ (noise increase) at $S t \approx 0.8-0.9$. As the corresponding Strouhal number is close to one, it is believed that the noise increase is caused by constructive interference $\left(360^{\circ}\right.$ phase angle) between the sources of the slit trailing edges. This is different to the destructive interference mechanisms which should occur at $S t=0.5,1.5$, and so on, between the roots and tips of the slit trailing edge. This is consistent with the experimentally observed destructive interference at $S t=0.3$ and a constructive interference at $S t=0.8$. 
Figure 13 shows the contour of $\triangle \mathrm{PWL}$ at various slit amplitude, $2 h$, against $f$ at different $U$. The results in Figure 13 clearly demonstrate the co-existence of destructive and constructive interference regions across all $U$ and $2 h$. Furthermore, peak noise reduction fits very well to the curve pertaining to a non-dimensional frequency of $S t=0.3$. This corresponds to the destructive interference mechanism between the roots and tips of the slits, which is illustrated in Figure 14. Similarly, constructive interference at $S t=0.8$ is confirmed by the measured noise increase.
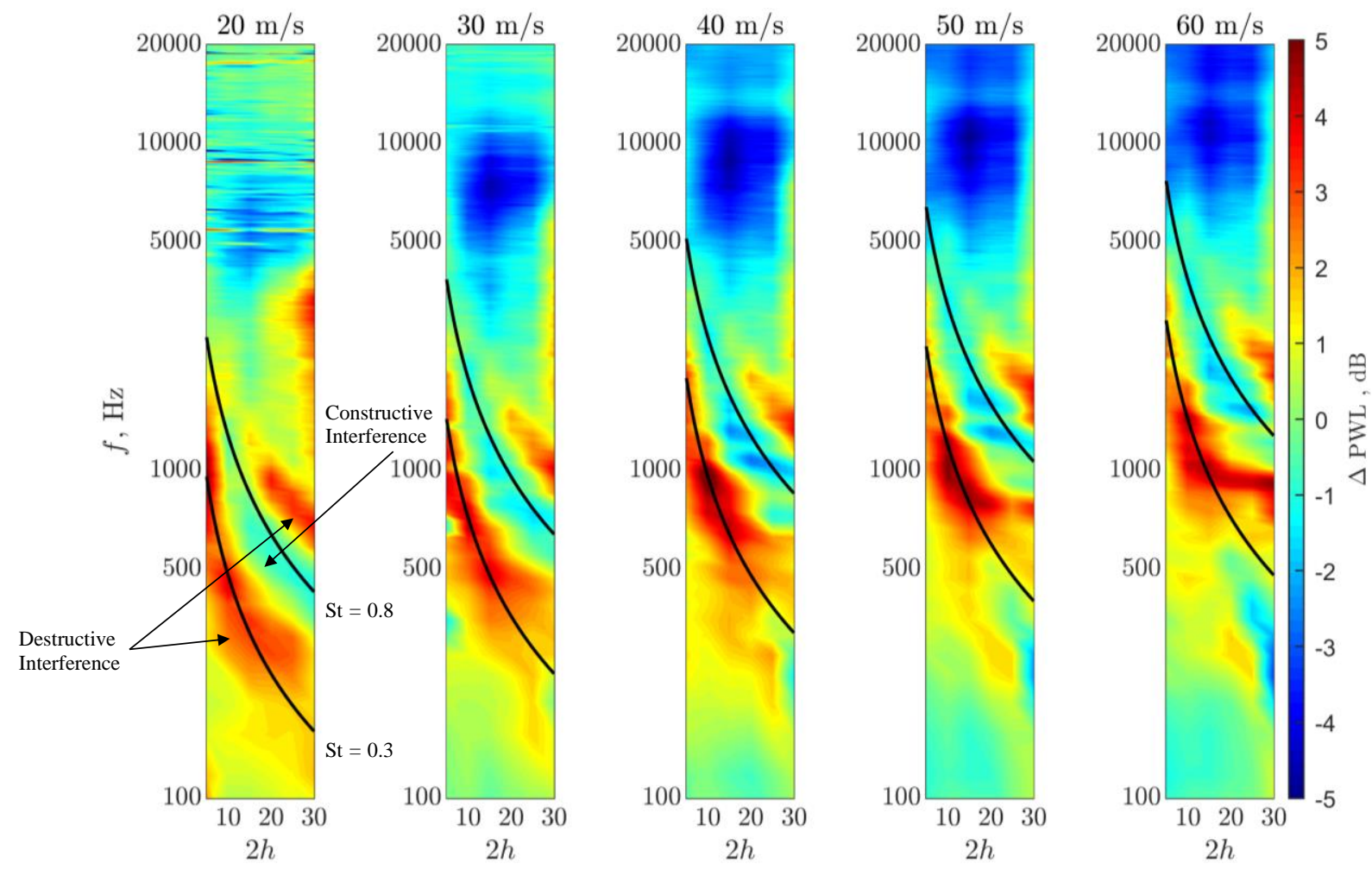

Figure 13: $\triangle \mathrm{PWL}$ contour maps of the frequency, $\mathrm{Hz}$, to $2 h$ for the Slit trailing edges at different freestream velocity, $U$.

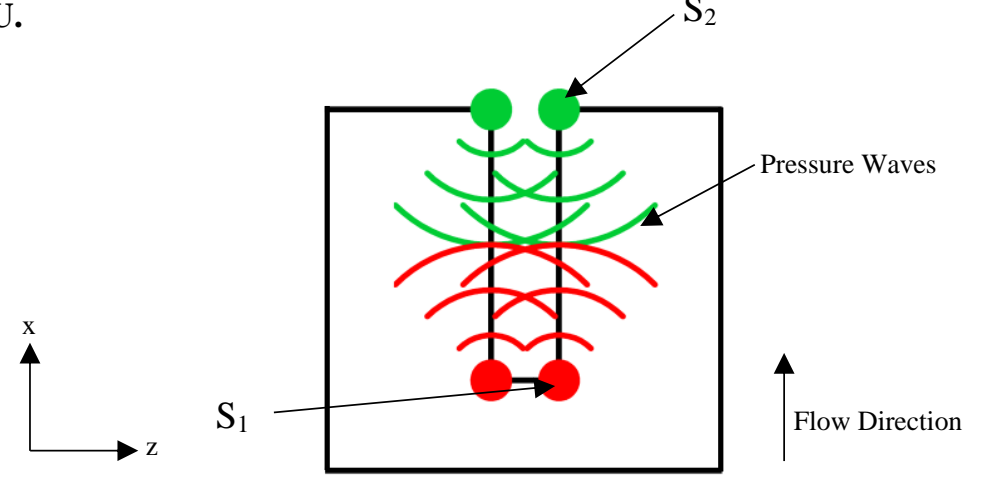

Figure 14: Diagram illustrating the sources $\left(S_{1} \& S_{2}\right)$ for slit trailing edge case.

\section{DRooTES}

\section{A. Comparison of the Noise Results by DRooTES with Different Serration Amplitudes}

Figure 15 presents the broadband noise radiations of DRooTES to B trailing edges of different $2 h$ and serration wavelength was kept at $\lambda=3 \mathrm{~mm}$. The best performer amongst all the DRooTES cases is with the largest amplitude $2 h=30 \mathrm{~mm}$, where noise reduction up to $4 \mathrm{~dB}$ at $U=20 \mathrm{~m} / \mathrm{s}$ and $6 \mathrm{~dB}$ at $U=60 \mathrm{~m} / \mathrm{s}$. The one that is atds refers to 
the $2 h=5 \mathrm{~mm}$ DRooTES, where noise reduction against the B trailing edge only occurs at high frequency. Overall, the decrease in amplitude for the DRooTES will lead to degradation of the level of noise reduction, consistent with the SRooTES case. At high frequencies, the DRooTES also follows the same trend as the SRooTES to produce noise increase up to $2 \mathrm{~dB}$. Yet, DRooTES with the largest amplitude $2 h=30 \mathrm{~mm}$ is observed to produce the least noise increases at the high frequencies amongst other DRooTES.

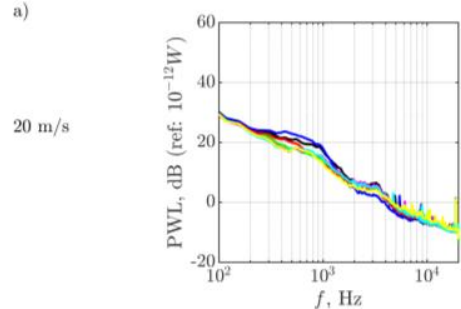

c)

$30 \mathrm{~m} / \mathrm{s}$

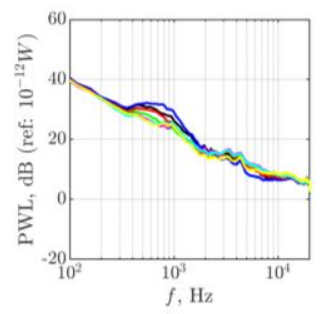

e)

$40 \mathrm{~m} / \mathrm{s}$

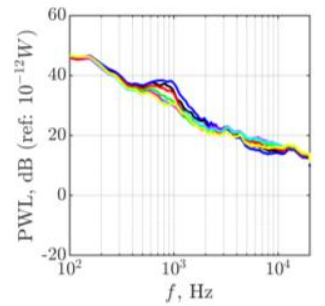

g)

$50 \mathrm{~m} / \mathrm{s}$

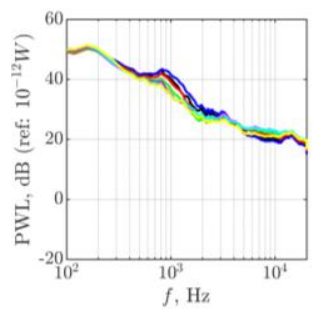

i)

$60 \mathrm{~m} / \mathrm{s}$

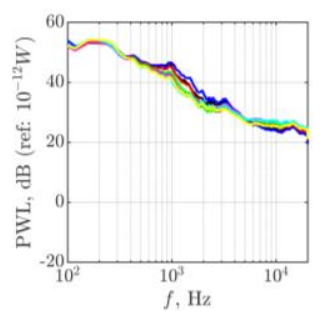

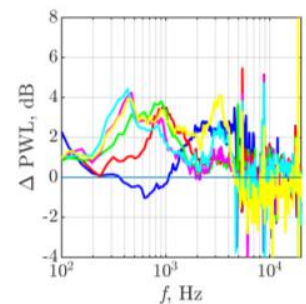
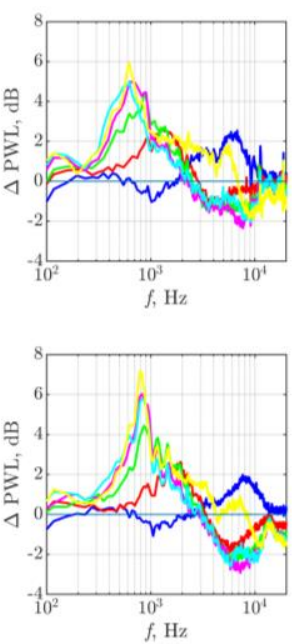

h)

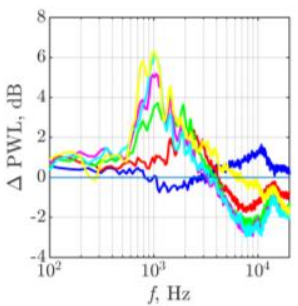

j)

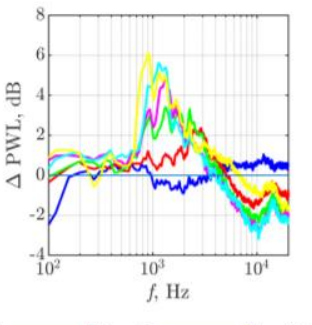

Figure 15: Comparison between the B and DRooTES (different $2 h$ ) trailing edges for: (a), (b) PWL, dB and (c), (d) $\triangle \mathrm{PWL}, \mathrm{dB}$, serration wavelength was kept at $\lambda=3 \mathrm{~mm}$ and at $\theta=0^{\circ}$. 


\section{B. Comparison of the Noise Results by DRooTES with Different Serration Wavelengths}

a)

$20 \mathrm{~m} / \mathrm{s}$

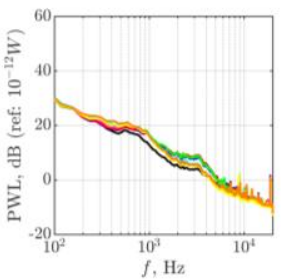

$30 \mathrm{~m} / \mathrm{s}$

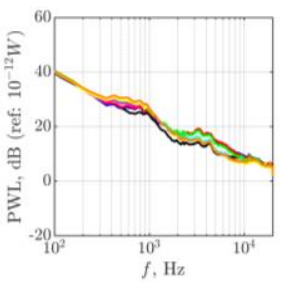

e)
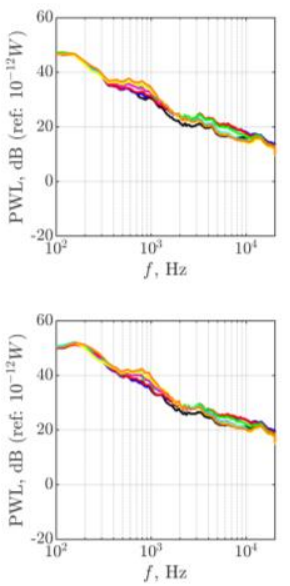

i) $60 \mathrm{~m} / \mathrm{s}$

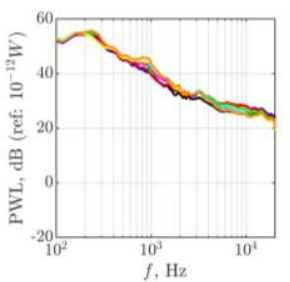

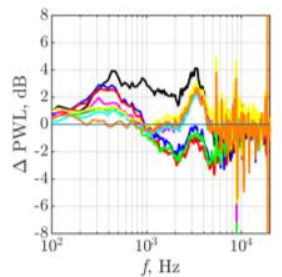
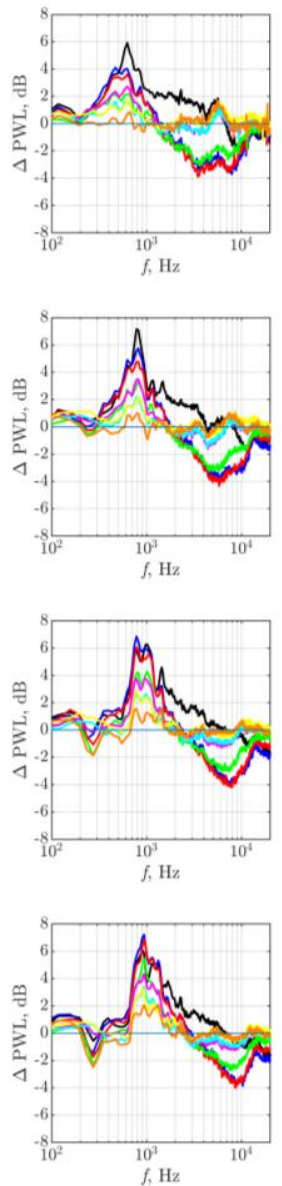

Figure 16: Comparison between the B and DRooTES (different $\lambda$ ) trailing edges for: (a), (b) PWL, dB and (c), (d) $\triangle \mathrm{PWL}, \mathrm{dB} .2 h=30 \mathrm{~mm}$ and $\theta=0^{\circ}$.

Figure 16 shows the sensitivity of the broadband noise radiation by the DRooTES with different $\lambda$. The best performer amongst the DRooTES is with $\lambda=3 \mathrm{~mm}$, where reduction up to $7.5 \mathrm{~dB}$ is observed. The increase of $\lambda$ for the DRooTES, again as expected, saw a degradation in the overall acoustic performance. The overall characteristic in the variation of $\lambda$ is similar to those of SRooTES in Figure 5. 


\section{Effect of Different $\boldsymbol{h}^{\prime}$ for the DRooTES}

a)

$20 \mathrm{~m} / \mathrm{s}$

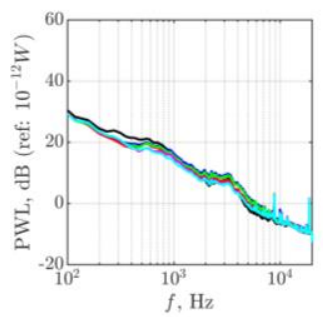

$30 \mathrm{~m} / \mathrm{s}$

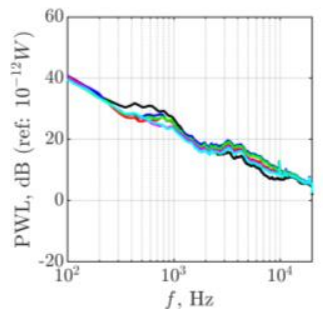

e)

$40 \mathrm{~m} / \mathrm{s}$

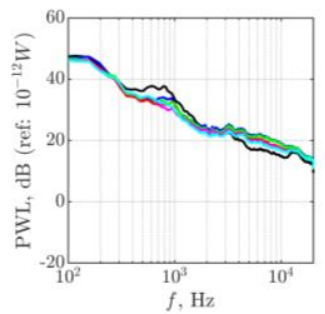

g)

$50 \mathrm{~m} / \mathrm{s}$

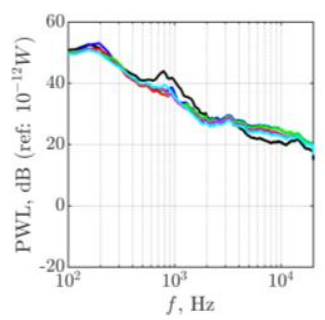

i)

$60 \mathrm{~m} / \mathrm{s}$

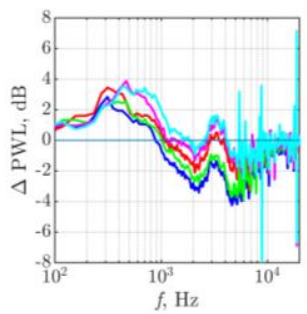

d)

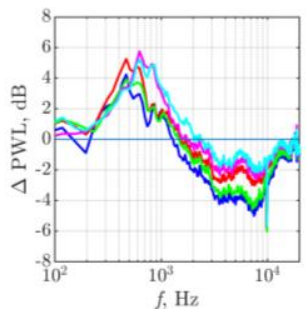

f)

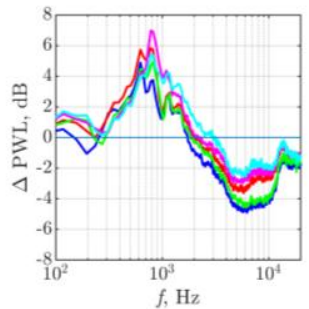

h)

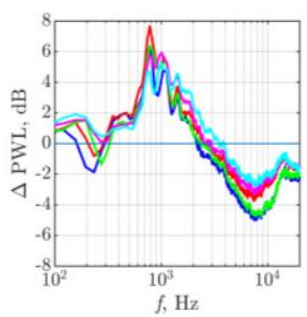

j)

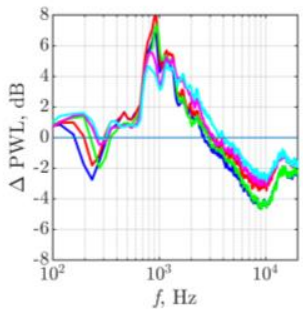

Figure 17: Comparison of different $h^{\prime}$ for DRooTES trailing edges for: (a), (b) PWL, $\mathrm{dB}$ and (c), (d) $\triangle$ PWL, dB. $2 h=30 \mathrm{~mm}, \lambda=6 \mathrm{~mm}$ and $\theta=0^{\circ}$.

For the DRooTES discussed so far, the root-root longitudinal displacement $\left(h^{\prime}\right)$ is always equal to the root-tip longitudinal displacement $\left(h^{\prime \prime}\right)$ for a particular $2 h$. Figure 17 shows the effect of broadband noise radiation of DRooTES at different $h^{\prime}$ under the same $2 h=30 \mathrm{~mm}$. The results clearly show a different behaviours in the peak $\Delta$ PWL. The smallest $h^{\prime}(\leq 10 \mathrm{~mm})$ is shown to be the most effective at low $U(\leq 40 \mathrm{~m} / \mathrm{s})$, with reduction up to $7 \mathrm{~dB}$. The mid-to-largest $h^{\prime}(>10 \mathrm{~mm})$ are the most effective at the high $U(>40 \mathrm{~m} / \mathrm{s})$ with reduction up to $8 \mathrm{~dB}$. The effects on the overall acoustic performance of the DRooTES highlights the importance of fine-tuning the $h^{\prime}$. It is worth stating that noise performance of the DRooTES with $2 h=30 \mathrm{~mm}, \lambda=6 \mathrm{~mm}$ and $h^{\prime}=20 \mathrm{~mm}$ (i.e. $h^{\prime \prime}=10 \mathrm{~mm}$ ) resulted in the largest noise reduction within this research. 


\section{Effect of $\phi$ for the DRooTES}

a)

$20 \mathrm{~m} / \mathrm{s}$

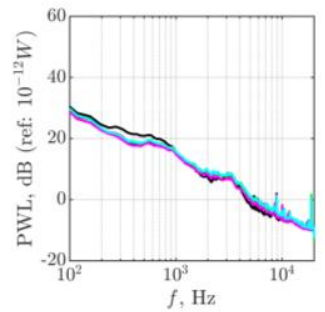

c)

$30 \mathrm{~m} / \mathrm{s}$

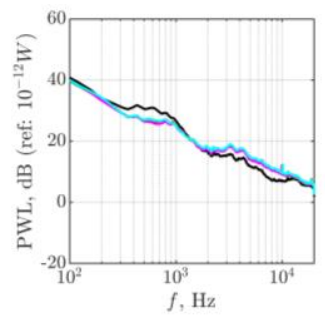

e)

$40 \mathrm{~m} / \mathrm{s}$

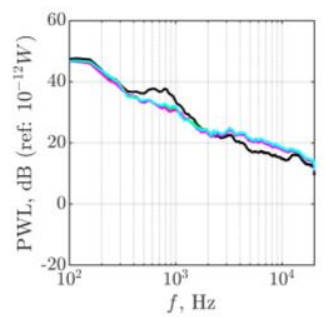

g)

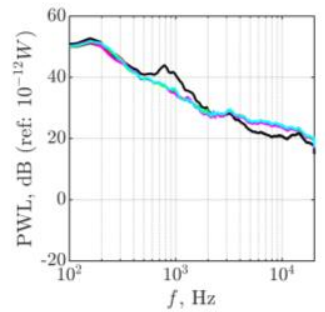

i) $60 \mathrm{~m} / \mathrm{s}$ b)

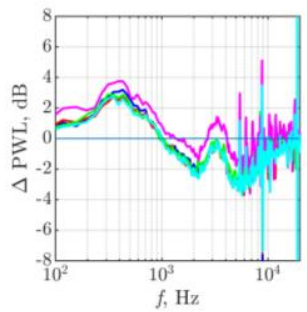

d)

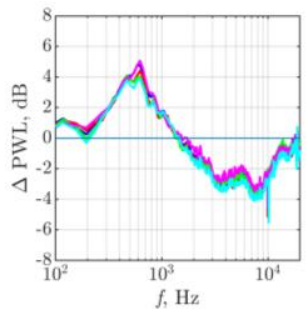

f)
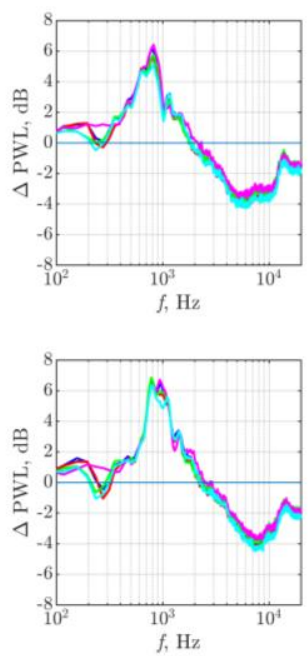

j)

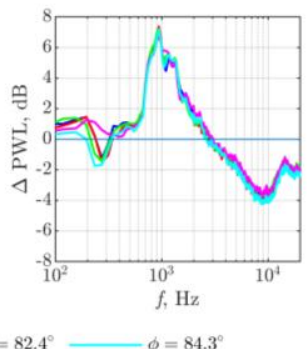

Figure 18: Comparison of $\phi$ of the DRooTES trailing edges where (a), (b) PWL, dB and (c), (d) $\triangle \mathrm{PWL,}$ dB. $2 h=30 \mathrm{~mm}$ and $\theta=0^{\circ}$.

Figure 18 examines the broadband noise radiation of DRooTES at various angle of the secondary serration tip $(\phi)$. The effect of $\phi$ offers little to no benefits to the overall acoustic performance for the DRooTES across the range of $U$ investigated here. However, $\phi=82.4^{\circ}$ has the best performance amongst the tested configurations. In summary, $\phi$ has no significant effect on the acoustic performance in comparison to the amplitude and wavelength of the DRooTES. 


\section{E. Non-Dimensional Frequency of DRooTES}

\section{i. DRooTES Amplitude}
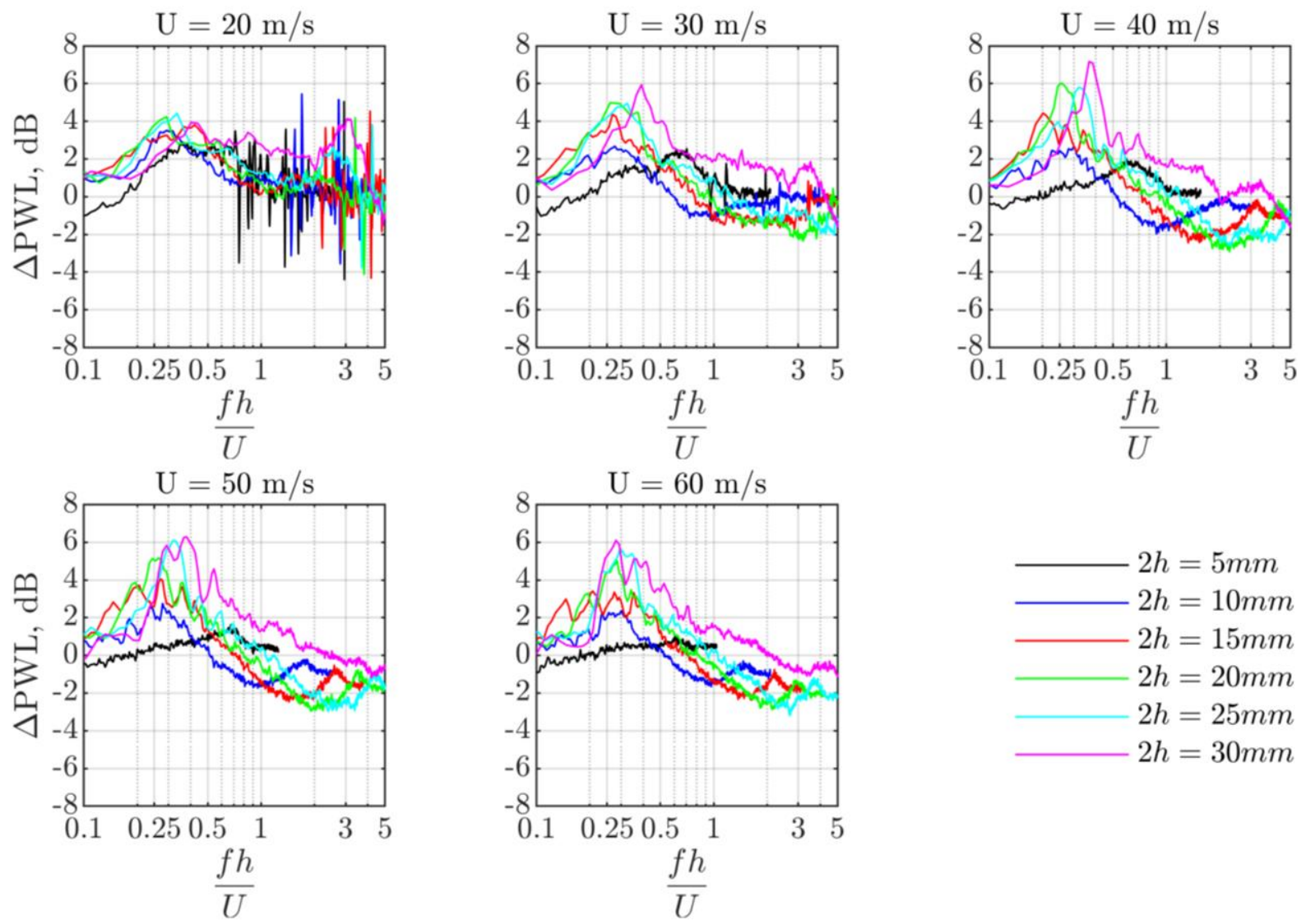

Figure 19: Non-Dimensional Frequency of the DRooTES at various amplitude $2 h, \lambda=6 \mathrm{~mm}, U=20 \mathrm{~m} / \mathrm{s}$ to $\mathrm{U}=\mathbf{6 0} \mathrm{m} / \mathrm{s}$ and $\theta=0^{\circ}$.

Figure 19 shows the spectra of $\triangle \mathrm{PWL}$ with non-dimensional frequencies. Assuming that destructive interference between the longitudinally displaced roots exists for the DRooTES, as shown in the schematic in Figure 20, the distance between them $(h)$ should be used for the Strouhal number. In addition, other two factors are added to the definition of the Strouhal number to account for the presence of secondary flow (to be discussed later) and the nonequal $h^{\prime}$ and $h^{\prime \prime}$. For destructive interference for a DRooTES, the following condition must be fulfilled:

$$
\frac{\omega h}{\bar{c} c u_{c}} k=\pi
$$

where $\omega=2 \pi f, \quad \bar{c} \approx 0.5, c=0.8$ and $k=\sqrt{\frac{h^{\prime \prime}}{h^{\prime}}} . \bar{c}$ accounts for the impacting factor for the propagation of the turbulent eddies as a result on the interaction with the pressure driven, oblique vortical structure at the sawtooth side edges as reported by Chong and Vathylakis ${ }^{22} . c$ is the fraction of freestream velocity, and $k$ is the empiricallydetermined factor to account for the non-equal between $h^{\prime}$ and $h^{\prime \prime}$. Therefore, the new definition for the Strouhal number appropriate for the DRooTES is:

$$
S t^{\prime}=\frac{f h}{c u_{c}} k=0.25
$$

When $h^{\prime}=h^{\prime \prime}, k=1$ and the peak $\Delta \mathrm{PWL}$ as a result of the destructive interference should occur at $S t^{\prime} \approx 0.25$ for the DRooTES. Indeed this has shown to be true in the results of Figure 19. 
Figure 21 shows contour of $\Delta \mathrm{PWL}$ at various serration amplitude, $2 h$, to frequencies at different freestream velocities. The results show destructive interference regions across all freestream velocities and serration amplitudes. This is confirmed by the similar curve to the non-dimensional frequency of $S t=0.25$ and broadband reduction follows a similar trend. However, unlike the slit trailing edge, the DRooTES did not exhibit constructive interference.

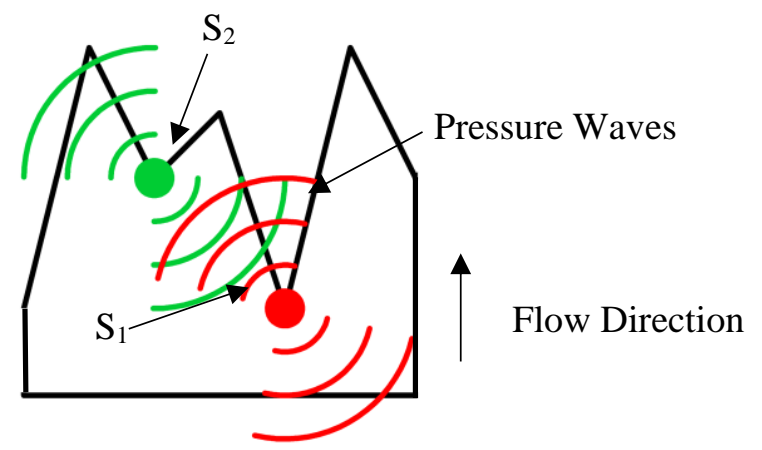

Figure 20: Diagram illustrating the sources and the longitudinal displacement $(h)$ between the sources $S_{1} \&$ $S_{2}$ for the DRooTES.
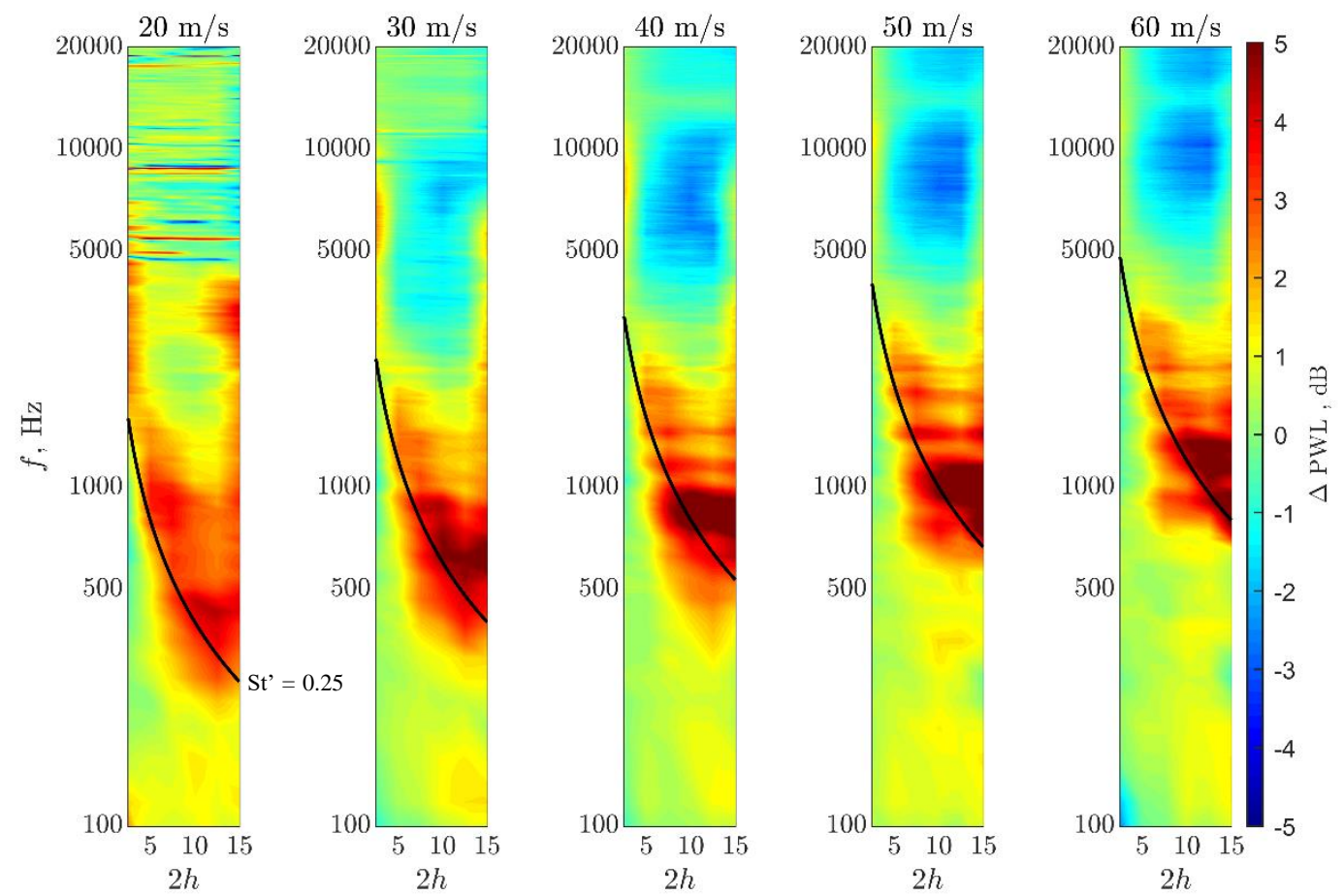

Figure 21: $\triangle \mathrm{PWL}$ contour maps of the frequency, $\mathrm{Hz}$, to $2 h$ for the DRooTES at different freestream velocity 


\section{ii. DROOTES Longitudinal Displacement between Roots - $\boldsymbol{h}^{\prime}$}
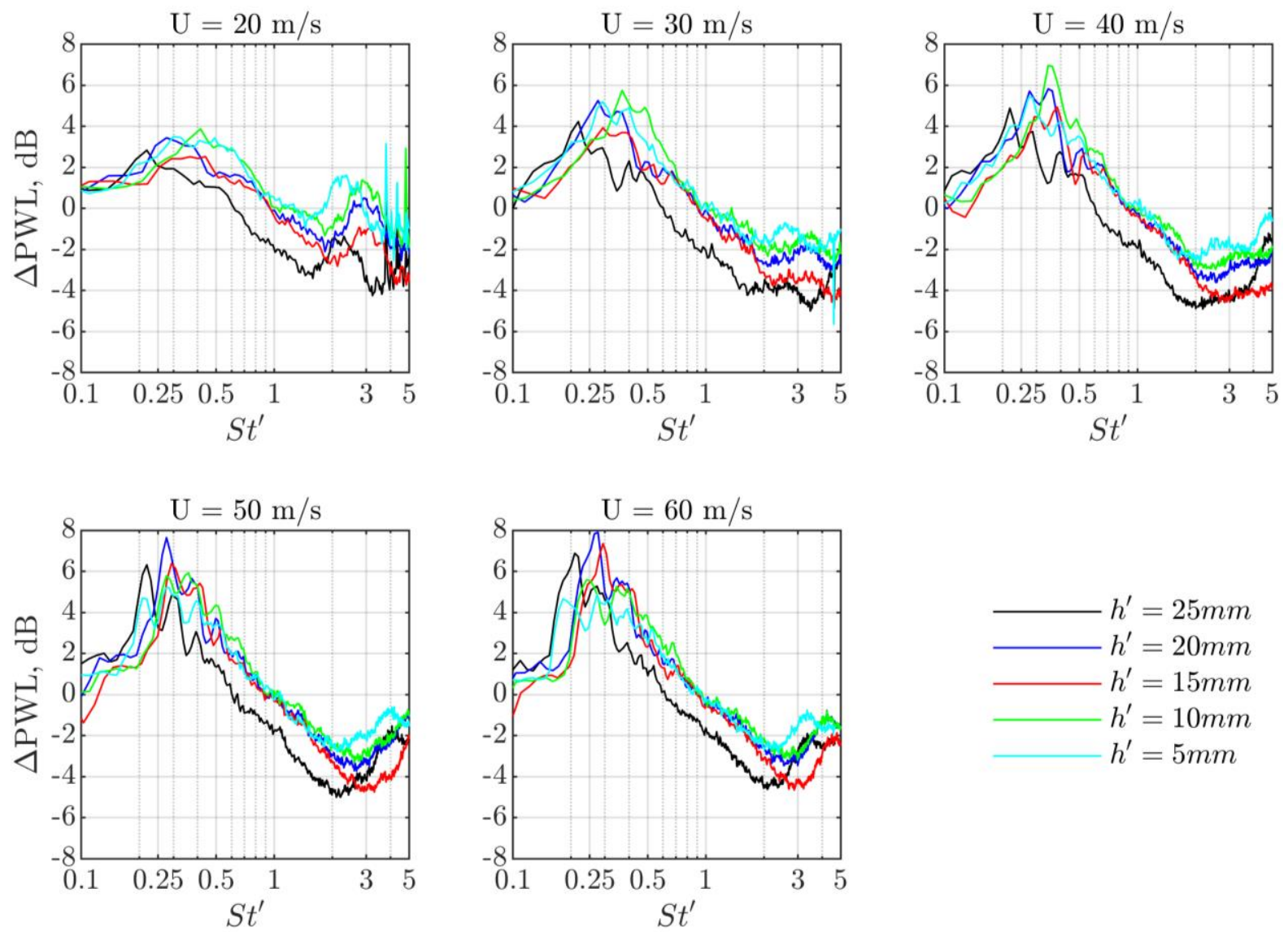

Figure 22: Non-Dimensional Frequency of the DRooTES at various longitudinal displace root, $h^{\prime}, \lambda=6$ $\mathrm{mm}, U=20 \mathrm{~m} / \mathrm{s}$ to $U=60 \mathrm{~m} / \mathrm{s}$ and $\theta=0^{\circ}$.

When $h^{\prime} \neq h^{\prime \prime}$, then $k$ is no longer a unity. Figure 22 shows the sensitivities of broadband noise radiation at nondimensional frequency at various $h^{\prime}$, where $2 \mathrm{~h}$ kept at $30 \mathrm{~mm}$. The result demonstrates that the different curves collapse reasonably well. The effect of increased $h^{\prime}$ has effect on the maximum noise reduction peak. The best performer was $h^{\prime}=20 \mathrm{~mm}$ with $8 \mathrm{~dB}$ reduction in comparison to the $h^{\prime}=5 \mathrm{~mm}$ achieving only $5 \mathrm{~dB}$ at same freestream velocity. However, the acoustic performance depended on both the geometrical parameters and flow conditions. 


\section{Conclusion}

This paper investigates the next-generation serration technology for aerofoil trailing edge self-noise reduction. The core of the technique is to employ phase-cancellation between two sources that are physically displaced in a longitudinal direction. The mechanism is known as destructive interference when an $180^{\circ}$ out of phase occurs between the two sources. To the best knowledge of the authors, this is the first report on the use of double rooted serration to optimise trailing edge self-noise reduction. The study investigated four trailing edge configurations, Baseline (B), Single-Rooted Trailing Edge Serrations (SRooTES), Double-Rooted Trailing Edge Serration (DRooTES) and Slit trailing edges. At low-to-mid frequency range, the SRooTES demonstrates benefits at broadband noise reductions by the smallest serration wavelength $(\lambda)$ and largest serration amplitude $(2 h)$. However, no evidence of destructive interference exists between the root and the tip for the SRooTES. The next configuration of slit trailing edge successfully demonstrates the destructive interference mechanism between the root and tip, although constructive interference (when the phase angle reaches $2 \pi$ ) also occurs which accounts for the noise increase at higher frequency. Finally, the DRooTES has been proven to execute the destructive interference mechanism effectively between the double roots of the sawtooth. As a result, the DRooTES can achieve larger noise reduction than the SRooTES. Most importantly, the DRooTES allows one to fine-tune the frequency of interest for the self-noise reduction under a certain flow speed. However, it should be noted that the frequency-tuning for the DRooTES should take into account of other factors such as the pressure-driven secondary flow at the sawtooth side edges that will affect the celerity of the turbulent eddies in the boundary layer.

\section{Acknowledgements}

The authors would like to thank the financial support from the EPSRC Doctoral Training Partnership (DTP) and the partial support from the EPSRC Research Grant No: EP/N018737/1 on the "Quiet Aerofoils on the Next Generation" to fund the equipment.

\section{Reference}

Chaitanya, P., and Joseph, P., "Slitted leading edge profiles for the reduction of turbulence-aerofoil interaction noise," The Journal of the Acoustical Society of America, vol. 143(6), Jun. 2018, pp. 3494-3504.

Pedersen, E., and Persson Waye, K., "Wind turbine noise, annoyance and self-reported health and well-being in different living environments," Occupational and Environmental Medicine, vol. 64, Jul. 2007, p. 480 LP486.

Civil Aviation Authority, "Aviation noise and health | UK Civil Aviation Authority" Available: https://www.caa.co.uk/Consumers/Environment/Noise/Aviation-noise-and-health/.

Knopper, L. D., and Ollson, C. A., "Health effects and wind turbines: A review of the literature," Environmental Health, vol. 10, Dec. 2011, p. 78.

Nissenbaum, M., Aramini, J., and Hanning, C., "Effects of industrial wind turbine noise on sleep and health," Noise and Health, vol. 14, 2012, p. 237.

European Commission, Flightpath 2050 Europe's Vision for Aviation, Publications Office of the European Union, 2011.

European Wind Energy Association, Wind energy scenarios for 2030, 2015.

Pinder, J. N., "Mechanical noise from wind turbines," Wind Engineering, vol. 16, 1992, pp. 158-168.

Tong, W., Wind power generation and wind turbine design, WIT Press, 2011.

Environmental Policy Group Department of the Environment, ., Draft PPS18: Renewable Energy, webteam.planning@doeni.gov.uk, 2007.

Oerlemans, S., Fisher, M., Maeder, T., and Kögler, K., "Reduction of Wind Turbine Noise Using Optimized Airfoils and Trailing-Edge Serrations," AIAA Journal, vol. 47, 2009, pp. 1470-1481.

Brooks, F., Stuart, D., and Marcolini, A., Airfoil Self-Noise and Prediction, 1989.

Hersh, A. S., Sodermant, P. T., Hay, R. E., and Hayden, R. E., "Investigation of Acoustic Effects of LeadingEdge Serrations on Airfoils," Journal of Aircraft, vol. 11, Apr. 1974, pp. 197-202.

Alan Hersh, B. S., and Hayden, R. E., Aerodynamic Sound Radiation from Lifting Surfaces with and without Leading-Edge Serrations.

Hansen, K., Kelso, R., and Doolan, C., "Reduction of Flow Induced Tonal Noise Through Leading Edge 
Tubercle Modifications," Acoustics Australia, 2012, pp. 172-177.

Chong, T. P., Biedermann, T., Koster, O., and Hasheminejad, S. M., "On the Effect of Leading Edge Serrations on Aerofoil Noise Production," 2018 AIAA/CEAS Aeroacoustics Conference, Reston, Virginia: American Institute of Aeronautics and Astronautics, 2018.

Clair, V., Polacsek, C., Le Garrec, T., Reboul, G., Gruber, M., and Joseph, P., "Experimental and Numerical Investigation of Turbulence-Airfoil Noise Reduction Using Wavy Edges," AIAA Journal, vol. 51, Nov. 2013, pp. 2695-2713.

Narayanan, S., Chaitanya, P., Haeri, S., Joseph, P., Kim, J. W., and Polacsek, C., "Airfoil noise reductions through leading edge serrations," Physics of Fluids, vol. 27, Feb. 2015, p. 025109.

Kim, J. W., Haeri, S., and Joseph, P. F., "On the reduction of aerofoil-turbulence interaction noise associated with wavy leading edges," Journal of Fluid Mechanics, vol. 792, Apr. 2016, pp. 526-552.

Vathylakis, A., Paruchuri, C. C., Chong, T. P., and Joseph, P., "Sensitivity of aerofoil self-noise reductions to serration flap angles," 22nd AIAA/CEAS Aeroacoustics Conference, Reston, Virginia: American Institute of Aeronautics and Astronautics, 2016.

1 León, C. A., Ragni, D., Pröbsting, S., Scarano, F., and Madsen, J., "Flow topology and acoustic emissions of trailing edge serrations at incidence," Experiments in Fluids, vol. 57, 2016.

Chong, T. P., and Vathylakis, A., "On the aeroacoustic and flow structures developed on a flat plate with a serrated sawtooth trailing edge," Journal of Sound and Vibration, vol. 354, Oct. 2015, pp. 65-90.

Gruber, M., Joseph, P., and Chong, T. P., "On the mechanisms of serrated airfoil trailing edge noise reduction," 17th AIAA/CEAS Aeroacoustics Conference (32nd AIAA Aeroacoustics Conference), Reston, Virigina: American Institute of Aeronautics and Astronautics, 2011.

Howe, M. S., "Noise produced by a sawtooth trailing edge," The Journal of the Acoustical Society of America, vol. 90, 1991, pp. 482-487.

Lyu, B., Azarpeyvand, M., and Sinayoko, S., "Prediction of noise from serrated trailing edges," Journal of Fluid Mechanics, vol. 793, 2016.

Gruber, M., "Airfoil Noise Reduction by Edge Treatments," PhD Thesis, Southampton University, 2012.

van der Velden, W. C., Avallone, F., and Ragni, D., "Numerical analysis of noise reduction mechanisms of serrated trailing edges under zero lift condition," 23rd AIAA/CEAS Aeroacoustics Conference, Reston, Virginia: American Institute of Aeronautics and Astronautics, 2017.

Vathylakis, A., "Reduction of broadband trailing edge noise by serrations," Brunel University London., 2015. Woodhead, P. C., Chong, T. P., and Wissink, J., "Exploiting the Misalignment of the Serrated Trailing Edge for Improved Aerofoil Broadband Noise Reduction," 23rd AIAA/CEAS Aeroacoustics Conference, Jun. 2017, pp. 1-16.

Vathylakis, A., Chong, T.P., Kim, J. H., "Design of a low-noise aeroacoustic wind tunnel facility at Brunel University," 20th AIAA/CEAS Aeroacoustics Conference, 2014, pp. 1-11.

Arce Leon, C. A., Merino Martinez, R., Ragni, D., Pröbsting, S., Avallone, F., Singh, A., and Madsen, J., "Trailing edge serrations: Effect of their flap angle on flow and acoustics," 7th International Conference on Wind Turbine Noise, 2017.

Dassen, T., Parchen, R., Bruggeman, J., and Hagg, F., "Results of a wind tunnel study on the reduction of airfoil self-noise by the application of serrated blade trailing edges," Proceeding of the European Union Wind Energy Conference and Exhibition, 1996, pp. 800-803.

Sagrado, A. G., "Boundary Layer and Trailing Edge Noise Sources," PhD Thesis, University of Cambridge, 2007. 